Document downloaded from:

http://hdl.handle.net/10251/160604

This paper must be cited as:

Serrano, J.; Arnau Martínez, FJ.; García-Cuevas González, LM.; Soler-Blanco, P.; Cheung, R. (2021). Experimental validation of a one-dimensional twin-entry radial turbine model under non-linear pulse conditions. International Journal of Engine Research. 22(2):390-406. https://doi.org/10.1177/1468087419869157

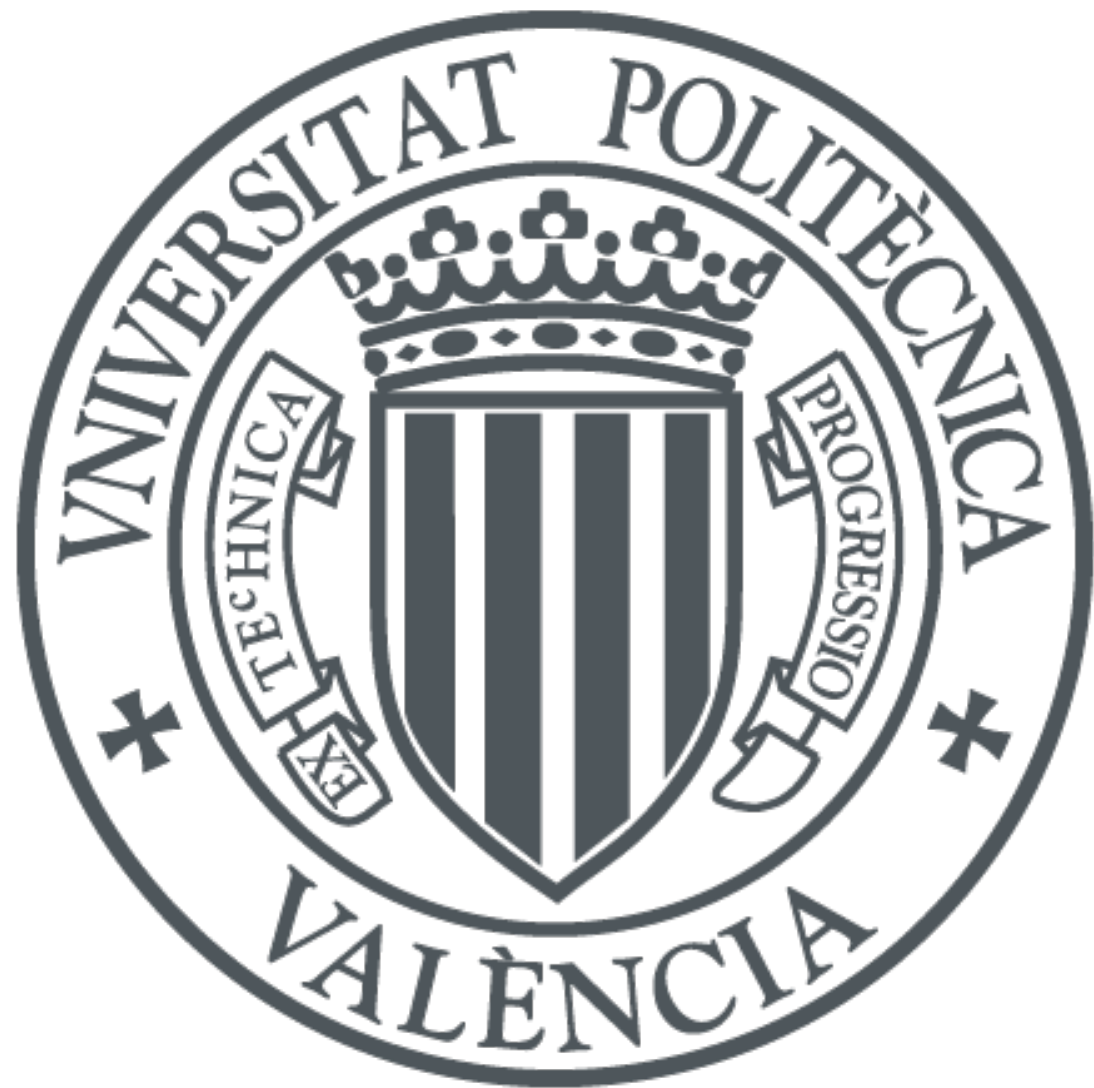

The final publication is available at

https://doi.org/10.1177/1468087419869157

Copyright SAGE Publications

Additional Information

This is the author is version of a work that was accepted for publication in International Journal of Engine Research. Changes resulting from the publishing process, such as peer review, editing, corrections, structural formatting, and other quality control mechanisms may not be reflected in this document. Changes may have been made to this work since it was submitted for publication. A definitive version was subsequently published as https://doi.org/10.1177/1468087419869157 


\title{
Experimental validation of a one-dimensional twin-entry radial turbine model under nonlinear pulse conditions
}

\author{
J.R. Serrano ${ }^{1}$, F.J. Arnau' ${ }^{1}$, L.M. García-Cuevas ${ }^{1}$, P. Soler ${ }^{1}$ and R. Cheung ${ }^{2}$
}

\begin{abstract}
This paper presents the experimental validation of a complete integrated 1D twin-scroll turbine model able to be used in reciprocating internal combustion engine unsteady simulations. A passenger car twin entry type turbine has been tested under engine like pulse conditions by means of a specifically built gas stand. To obtain high resolution quality data, the turbine and turbine line pipes have been instrumented with mean and instantaneous pressure sensors as well as temperature and mass flow sensors, employing a uniquely designed rotating valve for the pulse generation. This experimental configuration enables to obtain the pressure decomposition in both inlets and the outlet of the turbine. Using the experimental data obtained, the model is fully validated, with special focus in the reflected and transmitted components for analysing the performance of the model and its non-linear acoustics prediction capabilities. The model presents a very high degree of correlation with the experimental results, providing a range of error similar than the uncertainty of the measurements, even in the medium-high frequency spectrum.
\end{abstract}

\section{Keywords}

Turbocharger, One-dimensional model, Twin turbine, Pulsating flow, Instantaneous turbine performance

\section{Introduction}

The increasing stringent pollutant emissions legislations and the demand of low consumption and low emission vehicles has lead the automotive industry towards highly efficient engines. During the past few years, the turbocharging technology together with the downsized and rightsizing approach has been proved to be hugely effective, reducing dramatically the $\mathrm{CO} 2$ emissions among other pollutants [1]. The high percentage of recoverable energy available in the exhaust manifold [2] can be used in the turbine for driving the compressor and boosting the intake air for a more efficient combustion.

In spite of all the advantages of the use of turbochargers, the exhaust flow energy can be insufficient in some low engine speed operating conditions, leading to a lack of engine performance during transients. With its particular design of the housing, in which the flow is divided into two separated flow channels fed by separate exhaust banks, the two-scroll turbine decouples the energy pulses of alternative firing order cylinders, using the dynamic pressure effectively for optimising the scavenging effects. In this manner, multiple scroll turbines allow a better recovery of the dynamic pressure of the gas pulses [3] as they can avoid part of the backflows generated by interferences of exhaust processes between consecutive firing order cylinders and, thus, improve the engine volumetric efficiency. Due to their big valves overlap, important interferences can take place even in 4 cylinder engines. But not only gasoline engines, big diesel engines for truck and long haul engines with more than 4 cylinders, typically 6 cylinders, suffer significant overlapping effects and improve significantly their transient response when being turbocharged using two-scroll turbines. Fast one-dimensional, time-resolved simulations of twoscroll turbines under pulsating flow conditions become a valuable tool to analyse their behaviour during engine design and optimisation. The present work presents a model covering that use case, validated against pulsating flow experimental data.

This paper is structured as follows: first, the literature review and the experimental method to obtain the non-linear acoustic response of a two-scroll turbine are summarised; second, the model description and its adaptation to pulsating conditions is explained; third, the model is validated against the experimental data and the main results are analysed; finally, the main conclusions are presented.

\subsection{Literature review}

Due to the opening and closing of the cylinder valves during real driving conditions, the turbine is constantly operating under unsteady conditions [4]. And, thus, it is fundamental to correctly comprehend its behaviour not only in steady state but also in pulsating conditions. With this purpose, Winterbone et al. [5] and Winterbone and Pearson [6] performed a rigorous review on the topic. Investigators have also performed different experiments for pulsating flow in single entry turbines, such as Torregrosa et al. [7] or Serrano et al. [8] for unsteady and off-design performance, Torregrosa et al. [9] for diesel engines or Hohenberg et al. [10]. Piscaglia et al.[11] show an interesting approach, measuring the instantaneous pressure, temperature and mass flow in different points in the turbine inlet duct and the turbine outlet duct. Galindo et al. [12] present a similar

\footnotetext{
${ }^{1} \mathrm{CMT}$ - Motores Térmicos,Universitat Politècnica de València, ES

${ }^{2}$ Jaguar Land Rover Ltd, UK

Corresponding author:

Luis Miguel García-Cuevas, CMT - Motores Térmicos, Universitat Politècnica de València, Camino de Vera, Valencia 46022, Spain

Email: luiga12@mot.upv.es
} 
experimental methodology as the one presented in this paper, being applied for a variable geometry turbine. Finally, Cappelaere et al. [13] present a new test methodology for testing turbochargers under highly pulsating conditions.

Pulsating flow creates, however, unique operating characteristics in a two-scroll turbine compared to a single entry turbine that, furthermore, are highly sensitive to the flow distribution through the turbine entries. Baines et al. [14] studied the performance of a mixed flow vaneless radial turbine under pulsating conditions, performing pulses of different frequencies $(20-60 \mathrm{~Hz})$, and turbine speeds $(300-$ $500 \mathrm{rps}$ ). A more recent improved version of the experiments presented by Baines et al. [14] can be found in the work by Rajoo et al. [15], in which they were able to characterise the turbine behaviour under a given pulse flow, analysing also different vane angle settings as it was also exposed in previous works [16]. Some other contributions to the analysis of the twin and double entry performance under pulses are the ones carried out by Copeland et al. [17][18], where, in addition to the unsteady performance, a comparison with the turbine steady state performance is also presented. Costall et al. [19] documented some similar findings including the unsteady behaviour of a twin entry turbine for heavy duty nonroad applications in full and unequal admission conditions.

As it has been observed in this paper among others, it is considerably challenging to obtain reliable experimental results when measuring real pulse engine conditions. Because of that, some interesting studies have been performed using CFD that have contributed to the understanding of the turbine unsteady phenomena. M. Yang et al. [20, 21] presented the investigation of the influence of volute cross-sectional shape on the performance of a radial turbocharger turbine under pulsating conditions supported with experimental results. Copeland et al. [22] presented an investigation on the effect of the unequal admission on the performance of a double-entry turbine by means of a full 3D computational fluid dynamics (CFD) model. Most recently, M. Cerdoun and A. Ghenaiet [23] performed a study that characterises the flow behaviour of a twin-entry turbine under engine-like inlet flow conditions with a focus on the development of Dean vortices and the hysteresis phenomena.

CFD modelling application is, however, limited by its huge computational cost. In contrast, 1D and quasi1D models provide considerable accuracy with a much more manageable time required, reaching even real time capabilities for some applications. One-dimensional gas dynamic modelling include a vast range of variety and complexity among the different approaches when analysing the pulse performance. A first and computationally very affordable possibility is the "filling-emptying" model, as the ones presented by Baines et al. [14] and Payri et al. [24] In these cases, the volume of the twin-scroll housing is considered, what enables to predict the mass and energy accumulation effects. Nevertheless, in this paper the focus is set in the turbine acoustic characterisation with nonlinear capabilities and, thus, a wave action pulse flow model has been used. With this approach, and being furthermore application oriented, the works by Costall et al. [19] and Chiong et al. [25] can be found. In 2015, a more complex model was presented [26], using a loss parameters tuning criteria for twin-scroll modelling based on an approximation of the real physics. Following previous works developed in Imperial College, M. Chiong et al. [27] explore the potential improvement in the twin-entry pulse flow modelling by considering the unequal and partial admission conditions. Finally, Chiong et al. [28] present a revised 1D pulse flow modelling method to predict the twin-scroll turbine performance that is validated against experimental data, providing the technique to generate the full range of admission curves from the full admission experimental data.

Especially interesting is the contribution made by Kabral et al. [29], where an experimental methodology for performing an acoustic characterisation of the turbine with a pressure decomposition method is described, and the linear amplitude dynamic response of the twinscroll turbine is obtained. Furthermore, the technology described in detail in [30] provides the flexibility to analyse the non-linear response under different conditions (hot and cold), with different amplitudes and equivalent engine points of operation separating the effects of each branch independently. The experimental data obtained in [30] are validated in the present work against a onedimensional quasi-steady model providing a very good degree of correlation, that allows to predict accurately the characteristics of the pulse transmitted to the exhaust line and also reflected to the exhaust manifold, which implies more efficient decisions during the design and matching stages between turbocharger and engine.

The model presented in this paper has been used with pulsating flow and its results have been compared against experimental data. The pressure waves prediction in the frequency domain keep good accuracy for up to $1000 \mathrm{~Hz}$ or even more, while keeping the computational cost of the computations low. In single threaded simulations, the model needs 60 seconds for each single second of simulated time in an x86 CPU running at $3.2 \mathrm{GHz}$. It can easily be used coupled with other submodels of the turbocharger, taking into account the compressor quasi-steady map extrapolation [31], the heat transfer [32][33][34] or the mechanical losses in the bearings [35].

\subsection{Experimental campaign}

The experiments used for this validation study were performed in a specifically built gas stand in CMTMotores Térmicos as described in previous works [30]. The experimental results are available for download at https://www.cmt.upv.es/DD01.aspx. This facility is aimed to perform turbine acoustic characterizations under nonlinear pulse conditions by means of a rotating valve for generating the pulses and an array of instantaneous pressure sensors (piezoelectric) for the pressure decomposition as it will be detailed next. The turbine used in this study is a twin-entry radial inflow turbine, with wastegate and asymmetrical entry that is designed to be used in a D-segment passenger car, 2.0 L gasoline engine. Regarding the nomenclature adopted, shroud and hub will differentiate each entry referring to its location inside the housing.

The gas stand has been designed trying to maximise the flexibility when selecting the operating range of the turbocharger. Thus, it is straightforward to change between hot or ambient conditions as well as to switch the branch in which the pulses are being generated [30]. In Table 1, the 
operating conditions used during the experimental campaign are summarised. The test plan was designed to cover typical engine working conditions. In particular, for each mass flow ratio $(M F R)$, as defined in Equation 1, different equivalent engine speed have been tested using the rotating valve, starting in $1400 \mathrm{rpm}$ and up to $5600 \mathrm{rpm}$, through several intermediate speeds (3100, 3700, 3900 and $4800 \mathrm{rpm})$. The turbine expansion ratio and reduced mass flow was equivalent to that of engine torques between $25 \%$ and $50 \%$ of the maximum engine torque.

$$
M F R=\frac{\dot{m}_{\text {shroud }}}{\dot{m}_{\text {shroud }}+\dot{m}_{\text {hub }}}
$$

Figure 1 represents a basic scheme of the gas stand facility. A two-stage radial compressor is used to provide the air mass flow to the turbine, and the high volume plenums are aimed to stabilise the flow. When operating in hot conditions, a combustion chamber can easily be activated to heat the air to the desired turbine inlet temperature. The average temperature at the turbine inlet is controlled by changing the fuel flow in the combustion chamber, thus affecting the pressure waves propagation speed. For generating pulses of high non-linear amplitudes, an especially designed rotating valve is situated in one of the inlet branches and activated by an electrical motor. A plate with three equispaced orifices is placed in the turbine side to limit the passing flow in a way that, considering that a complete rotation of the motor shaft produces three pulses, the desired pulse frequency can be easily obtained. An amplitude valve is operated by a PID controller in order to correctly control the amplitude of the pulses being generated. Although the rotating valve is fixed in one of the turbine inlet branches, the flexible pipes installed before the rotating valve allow to easily switch between inlet pulsating branches.

For the average flow pressure, piezoresistive sensors have been used in both compressor and turbine inlets and outlets as well as K-type thermocouples for the inlet and outlet temperatures. When the flow is divided into the two turbine branches, the measurements of the mass flow are obtained using V-cone mass flow meters, while a thermal mass flow meter is used for the compressor inlet flow and a vortex-type flow meter for the compressor outlet flow. Although with the current arrangement the V-cone flow meters do not provide high frequency, time-resolved pulsating flow measurements, they provide accurate average mass flow rate readings. It is also necessary to control and monitor the oil circuit, which is used for the rotating valve and also the turbocharger. To do so, pressure and temperatures are taken in both inlet and outlet sections of the oil circuit, using a Coriolis-type flow meter for the oil mass flow. Finally, to satisfy the accuracy and time resolution requirements, piezoelectric sensors have been used for the instantaneous pressure measurements. A beamforming method, described [36] and also proved [7] in previous works, has been used for performing the pressure decomposition. For the data acquisition, a specifically built automatic system based on PXI and RIO modules of National Instruments has been used. In Table 2, a summary of the instrumentation used in the experimental campaign can be found. Furthermore, in Table 3, there is a summary of the main controlling valves used during the experiments.

\subsection{Quasi-adiabatic and non-linearity assessment}

The experiments were performed in quasi-adiabatic conditions, minimising the external and internal heat transfer in the turbocharger and in the inlet and outlet ducts. Also, several thermocouples were used to get the average temperatures, thus minimising the typical inaccuracies found when measuring the turbine outlet temperature[37][38]. The overall energy balance was used to check the quality of the results, as explained by Serrano et al. [39].

In Figure 2 the relation between the power of the external heat and the turbine power is shown, providing, directly, the expected error in the calculation of the turbine power output due to the external heat flow losses. The heat flow to the ambient is situated below $0.5 \%$ of the measured turbine power output, which indicates an effective thermally insulation of the ducts in the controlled laboratory conditions. Thus, the heat flow to the ambient is low enough to consider quasi-adiabatic experimental conditions for all the operating points.

To estimate the heat flow to the ambient, Equation 2 is used:

$$
\dot{Q}_{\mathrm{env}}=A_{\mathrm{surf}} \cdot h_{\mathrm{conv}} \cdot\left(T_{\mathrm{surf}}-T_{\mathrm{env}}\right)
$$

where $T_{\text {env }}$ is the environment temperature, $T_{\text {surf }}$ is the maximum surface temperature of the insulation, $A_{\text {surf }}$ is the exposed surface of the insulation, and the convective heat transfer coefficient $h_{\text {conv }}$ is $10 \mathrm{~W} \mathrm{~m}^{-2} \mathrm{~K}^{-1}$. Note that the temperature difference between the insulation and the surroundings was low enough that the radiation was much smaller than the external convection.

On the other hand, the turbine power is estimated using the total enthalpy flow as in Equation 3:

$$
\dot{W}=\dot{m} \cdot c_{\mathrm{p}} \cdot\left(T_{6 \mathrm{t}}-T_{0 \mathrm{t}}\right)-\dot{Q}_{\mathrm{int}}
$$

where $\dot{Q}_{\text {int }}$ expresses the internal heat losses from the gas to the turbine, calculated as explained by Serrano et al. [40].

It is worth noting that the experimental data used to validate this model has been obtained in a gas stand using pressure pulses that have been generated by means of a rotating valve. It is then necessary to assess the amplitude and non-linearity of the pulses generated. Using data measured at a same turbine operating point but different pulse shapes, the study presented by Serrano et al. [30] gives a mathematical proof of the non-linearity of the excitations, indicating that the pulses were strong enough to induce realistic non-linear conditions in the turbine. The experimental data obtained is then reliable enough to evaluate the capability of the model presented in this work to predict the turbine behaviour under high-amplitude pulsating flow typical of engine operation.

\section{Model description and quasi-steady adaptation}

In this section, the twin-turbine 1D model developed in CMT is first presented, In addition, the modelling characteristics that have been necessary to incorporate to provide the model with unsteady capabilities are detailed. 


\begin{tabular}{ccccc}
\hline Case label & Pulsating branch & Approximate $M F R$ & Equivalent engine speed & Conditions \\
\hline$\# 1-\# 3$ & Shroud & $0.5-0.7$ & $1400 \mathrm{rpm}$ & Cold \\
$\# 4-\# 6$ & Shroud & $0.5-0.7$ & $3100 \mathrm{rpm}$ & Cold \\
$\# 7-\# 9$ & Shroud & $0.5-0.7$ & $3900 \mathrm{rpm}$ & Cold \\
$\# 10-\# 12$ & Shroud & $0.5-0.7$ & $4600 \mathrm{rpm}$ & Cold \\
$\# 13-\# 16$ & Hub & 0.5 & $1400 \mathrm{rpm}$ to $4600 \mathrm{rpm}$ & Cold \\
$\# 17-\# 20$ & Hub & 0.5 & $1400 \mathrm{rpm}$ & Cold \\
$\# 21-\# 24$ & Hub & $0.3-0.5$ & $3100 \mathrm{rpm}$ & Cold \\
$\# 25-\# 28$ & Hub & $0.3-0.5$ & $3900 \mathrm{rpm}$ & Cold \\
$\# 29-\# 32$ & Hub & $0.3-0.5$ & $4600 \mathrm{rpm}$ & Cold \\
$\# 33-\# 40$ & Shroud & 0.7 & $1900 \mathrm{rpm}$ to $5600 \mathrm{rpm}$ & Hot \\
$\# 41-\# 48$ & Hub & 0.3 & $1900 \mathrm{rpm}$ to $5600 \mathrm{rpm}$ & Hot \\
\hline
\end{tabular}

Table 1. List of the experimental points

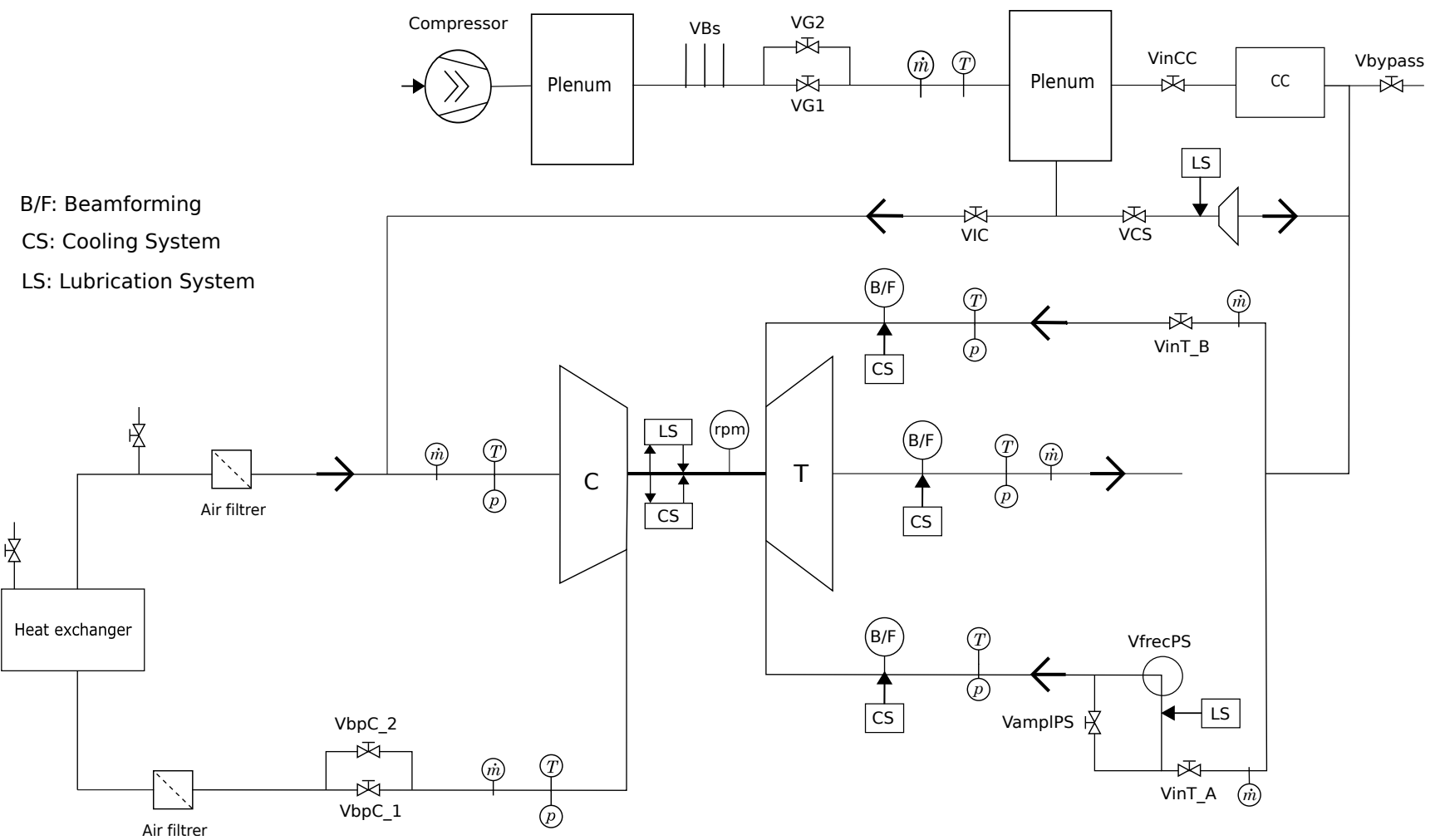

Figure 1. Turbocharger gas stand facility layout at CMT-Motores Térmicos

\begin{tabular}{cccc}
\hline Variable & Sensor & Sketch symbol & Uncertainty \\
\hline Gas pressure (mean) & Piezoresistive & $p$ & $12.5 \mathrm{hPa}$ \\
Gas pressure (instantaneous) & Piezoelectric & $\mathrm{B} / \mathrm{F}$ & $<0.1 \%$ \\
Gas/metal temperature & K-type thermocouple & $T$ & $1.5 \mathrm{~K}$ \\
Gas mass flow & V-cone, thermal, vortex & $\dot{m}$ & $<2 \%$ \\
Oil pressure & Piezoresistive & $\mathrm{LS}$ & $12.5 \mathrm{hPa}$ \\
Oil temperature & RTD & $\mathrm{LS}$ & $<0.5 \mathrm{~K}$ \\
Oil mass flow & Coriolis & $\mathrm{LS}$ & $2 \%$ \\
Turbo speed & Inductive sensor & $\mathrm{rpm}$ & $<500 \mathrm{rpm}$ \\
\hline
\end{tabular}

Table 2. Measurement instrumentation characteristics and corresponding symbols in the sketch of Figure 1

\subsection{Model domain}

In order to build the turbine model domain, the authors have used the previous experience in the 1D approach for single entry turbine modelling described by Serrano et al. [41]. The authors have also used their previous experience in single entry turbine efficiency and mass flow parameters extrapolation [42] [43]. The contrasted robustness and accuracy of the previous single entry version of the model reinforced the idea of a simple two-volutes adaptation of the existing model. The main source of obstacles during the modelling process will emanate from the flow effects that the interaction between the two scrolls will produce. 


\begin{tabular}{ccc}
\hline Valve & Action & Symbol in the sketch \\
\hline Vent valve & Open valve & VBs \\
General valves & Control flow & VG1, VG2 \\
Combustion chamber valve & Control cold air & VinCC \\
Cold air valve & Control cold air & VCS \\
Compressor entry valve & Control compressor flow & VIC \\
Bypass valve & Outlet combustion chamber & Vbypass \\
Turbine entry valve & Control turbine inlet flow & VinT_A, VinT_B \\
Pulse amplitude valve & Control amplitude pulse & VamplPS \\
Backpressure valve & Control backpressure & VbpC_1, VbpC_2 \\
Pulse frequency valve & Rotating valve frequency & VfrecPS \\
\hline
\end{tabular}

Table 3. Controlling valves and corresponding symbols in the sketch of Figure 1

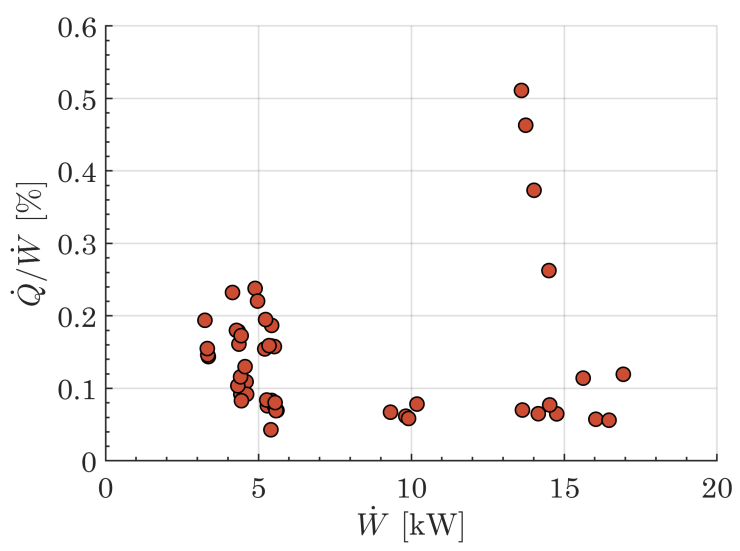

Figure 2. Relative external heat flow

In Figure 3 a basic sketch of the model domain is presented. Straight ducts have been used for the inlets and outlet pipes. The volutes are also one-dimensional, with an equivalent length of half of the developed volute, as first described originally by Chen and Winterbone [44, 45]. The stator is modelled as a zero-dimensional element with a volume equal to that of the physical stator and rotor combined, to take into account their mass and energy accumulation effects. The model shown in Figure 3 covers the computational flow domain from the measurement plane in the inlet (section 0), till the open end in the gas stand outlet pipe (section 7). Section 1 indicates the beginning of the turbine with the inlet duct, while section 2 references the volute inlet. Section 3 is the volute outlet and section 4 is the equivalent zero-dimensional element outlet. Section 5 represents the conditions after the rotor. Section 6 and 7 are the turbine outlet and the domain outlet, respectively.

Using straight ducts to simulate the volute flow with an equivalent length equal to half of the developed volute keeps the complexity of the model low while reproducing with high accuracy one of the main sources of linear and non-linear acoustics effects of the turbine. Also, although using three equivalent nozzles and an intermediate volume instead of just two equivalent nozzles seems to introduce some complexity, but it has several important advantages:

- It is closer to the real geometry of the turbine.

- It allows to model some mass and energy accumulation, wave and thermal transient effects.
- The effect that the addition of an intermediate volume produces has been deeply studied previously [12], producing significant improvements in the prediction for the middle and high frequency spectra.

- It reduces the stabilisation and initialisation issues that may arise during the calculations due to its damping effects.

- In the case of the need to speed up the calculation evolving this model to a 0D approach, this model gives quite a straight-forward solution.

In the following sections the model will be further detailed. The focus of this paper is, however, the adaptation and modification of the baseline steady-state model in order to provide it with unsteady capabilities, as explained in subsection 2.4.

\subsection{Method of calculation}

The simulation results that are presented in this study were obtained using OpenWAM [46], the 1D simulation integrated tool developed in CMT-Motores Térmicos. Euler classical governing equations for fluid dynamics are discretised across the set of OD and 1D elements of the computational domain. The set of equations that are discretised and solved are shown in Equation 4 and Equation 5.

$$
\begin{gathered}
\mathbf{w}=\left(\begin{array}{c}
\rho \\
\rho \cdot u \\
\rho \cdot e_{t}
\end{array}\right)=\left(\begin{array}{c}
\rho \\
\rho \cdot u \\
\rho \cdot c_{v} \cdot T+\rho \cdot u^{2} / 2
\end{array}\right) \\
\frac{\partial \mathbf{w}}{\partial t}=\frac{\partial}{\partial x}\left[\begin{array}{c}
\rho \cdot u \\
\rho \cdot u^{2}+p \\
\rho \cdot u \cdot\left(c_{p} \cdot T+u^{2} / 2\right)
\end{array}\right]
\end{gathered}
$$

where $\mathbf{w}$ is the state vector, $\rho$ is the density, $u$ is the flow speed, $e_{t}$ is the specific total internal energy, $c_{v}$ is the isochoric specific heat capacity, $T$ is the fluid temperature, $t$ is the time, $p$ is the gas pressure and $c_{p}$ is the isobaric specific heat capacity. An ideal gas equation of state is also used, as in Equation 6:

$$
p=\rho \cdot R \cdot T
$$

where $R$ is the gas constant. The older two-step LaxWendroff scheme in finite differences [47] was replaced by a Finite Volume Method, leading to a better result in terms of mass, momentum and energy conservation. 


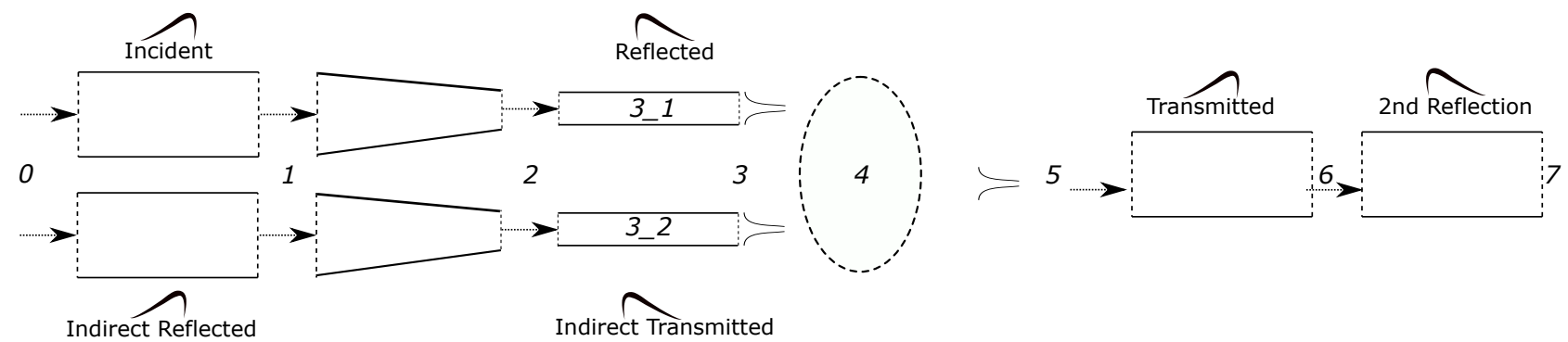

Figure 3. Twin turbine model computational domain. The main sections are labelled with numbers

After discretising the equations by a Finite Volume Method approach, Equation 7 is obtained:

$$
\frac{\mathrm{d} \overline{\mathbf{w}}_{i}}{\mathrm{~d} t}=\frac{\left(A_{i-1, i} \cdot \mathbf{F}_{i-1, i}-A_{i, i+1} \cdot \mathbf{F}_{i, i+1}+\mathbf{C}_{i}\right)}{V_{i}}
$$

where $\overline{\mathbf{w}}_{\mathbf{i}}$ is the mean value of the state vector in the cell $i, A_{i-i, i}$ is the boundary surface between cells $i-1$ and $i, \mathbf{F}_{i-1, i}$ is the flux vector between cells $i-1$ and $i$ and $\mathbf{C}_{i}$ is the source terms vector affecting cell $i$. Finally, $V_{i}$ is the volume of the cell. The source term is computed as in Equation 8 when no mass or heat sources are present:

$$
\mathbf{C}_{i}=\left[\begin{array}{c}
0 \\
p_{i} \cdot\left(A_{i-1, i}-A_{i, i+1}\right) \\
0
\end{array}\right]
$$

A Godunov-derived scheme reconstruction ([48]) was implemented, using a second order Monotone Upstreamcentered Scheme for Conservation Laws (MUSCL) [49] for improving the spatial accuracy during the integration. The linear extrapolation of the state vector to the cell boundaries is limited using a monotonised central slope limiter by van Leer, and the fluxes are computed using the Harten-Lax-van Leer-Contact approximate Riemann solver [50].

The time-step is obtained at each iteration following the Courant-Friedrichs-Lewy (CFL) condition [51], as in Equation 9:

$$
\Delta t=\left.v \cdot \frac{\Delta x}{\lambda}\right|_{\min }=\left.v \cdot \frac{\Delta x}{|u|+|a|}\right|_{\min }
$$

where $v$ is the Courant number, $\Delta x$ is the cell size, $\lambda$ is an eigenvalue of the system, $a$ is the speed of sound and the subscript min represents the minimum value. The Courant number used during the simulations was 1.0.

The value of the fluxes in both branches in section 3 and section 5 of Figure 3 are computed interpolating in the turbine map as described in the following sections. After computing all the terms, Equation 7 is solved each time-step by means of Heun's method.

\subsection{Baseline model}

The objective of this section is to provide an understandable reference framework for exposing the necessary modelling steps described in the next section, that have been followed in order to evolve the model to a quasi-steady integrated model with non-linear unsteady capabilities.
In this model approach, which is based on hypothesis presented by Serrano et al. [43], the turbine can be modelled as an equivalent nozzle with an equivalent area. This area varies on the operative conditions in a way that, assuming an adiabatic expansion, it is possible to obtain a full range of equivalent areas for each vane position in variable geometry turbines. This effective area model mainly depends on some main geometrical parameters that are easily measurable, the limited range of measured points that the manufacturer provides, and the corresponding fitting coefficients. With a similar procedure, the efficiency model [42] is based on the Euler equation of turbomachinery for radial gas turbines assuming some simplifications. Again, it uses the limited map provided by the manufacturer and some geometrical information, to provide a complete set of efficiency maps for each VGT configuration that are related also by fitting coefficients.

With a new and innovative approach, the previous [42] and [43] turbine extrapolation model [42] [43] can be adapted for two-scroll turbine. Using an approach of considering the two entries as individual turbines, it is possible to obtain a set of maps of effective area (and, thus, reduced mass flow) for each of the entries that will depend on the mass flow ratio instead of on the VGT position [39]. Once the equivalent nozzle area is obtained, the reduced mass flow in both entries, shroud and hub, can be calculated assuming an isentropic expansion through a nozzle. On the other hand, the efficiencies are obtained considering the enthalpy drop generated by each individual turbine as a difference between each inlet and the common outlet. Thus, two different set of efficiency maps are obtained for each inlet, that are related to the effective area maps. This steady-state interpolation and extrapolation model is described in detail by Serrano et al. [52].

\subsection{Pulsating flow model capabilities}

In this section, the different stations depicted in Figure 3 will be referred when needed but without explicit reference to Figure 3 for improving section readability. During unsteady simulations, the different one-dimensional elements are computed solving Euler equations of one-dimensional fluid dynamics, and the intermediate volume is computed solving its mass and energy conservation equations. The flow in stations 3, 4 and 5 is computed using a technique [41] to split the pressure ratio in the turbine between stator and rotor representing nozzles (stations 3 and 5 respectively in Figure 3). Heat transfer effects are taken into account as an energy source term changing the flow temperature when passing between stations 3 and 5, and an extra energy sink 
term is introduced in the intermediate volume 4 equal to the power output of the turbine each time step. The extrapolated turbine map [52] is used to compute the stator (3) and rotor (5) nozzles using techniques [41]. The efficiency is quasisteadly obtained [52].

The first obstacle to solve when building this model was the mass flow time-marching calculation. To obtain the areas of the nozzles at any time step, the mass flow ratio, the pressure ratio between the inlet of station 3 and the outlet of station 5 for each branch, the reduced rotational speed of each branch and the isentropic efficiency of each branch are needed [52]. When simulating only steady state conditions, this approach is accurate enough for generating correct mass flow results. In unsteady flow simulations this may not be the case, as the conditions at the beginning of each time step are used to compute this effective section in an explicit time integration scheme. Unsteady flow simulations may generate zero or reverse flow in station 3 for one of the volute branches instantaneously and, as a consequence, a mass flow ratio equal to 0 or 1 . The next time step, the effective section of that nozzle is computed with this mass flow ratio, which leads to an effective section equal to 0 . This way, the mass flow ratio is again 0 or 1 , and the process is repeated until the simulation finishes. For confronting this difficulty, instead of computing the mass flow ratio with the conditions in stations 3 and 5, the mass flow per branch is obtained using station 1. This way, whenever the effective section of one of the nozzles is equal to 0 , it can change to a bigger value in the following time steps when a pressure gradient produces again any amount of mass flow in station 1.

Using the mass flow ratio from station 1 to compute the effective section downstream can introduce some instabilities on its own. In reality, any change in the conditions in station 1 should take some time to reach stations 3 and 5 , of the order of $1 \mathrm{~ms}$ for the geometry tested in this manuscript. The authors found that, indeed, filtering the mass flow ratio with a first order delay of $1 \mathrm{~ms}$ produced optimal results for the studied turbine. The sensitivity of the results to this delay is small, so only the order of magnitude is actually needed.

The single entry turbine effective section model computes a single-nozzle equivalent section [41] and, after that, shares this between two equivalent nozzles with an intermediate volume [41]. The steady-state pressure of this volume is computed from the turbine efficiency, the rotor geometry and the degree of reaction to get the equivalent section of the two nozzles. In the case of a twin-entry turbine, the steady-state pressure of the intermediate volume is computed as a mass flow ratio-weighted average of the steady-state pressure obtained for each turbine branch as a single entry turbine. This way, the effective section of each stator nozzle is computed, as well as two effective sections for the rotor nozzle, one for each branch. The final rotor nozzle effective section is the sum of the result of each branch. When the pressure difference between branches is high enough, backflow between them can appear naturally before the rotor nozzle.

The efficiency of each branch is computed as a function of its blade speed ratio, reduced speed, mass flow ratio and effective section [52]. As the effective section is a function of the efficiency and the efficiency is a function of the effective section, the results are obtained in an iterative process [52].

With the efficiency and the effective sections, the mass flow of the three nozzles is computed and used as boundary conditions for the different one-dimensional and zerodimensional elements connected to them. With the mass flow of each stator nozzle and its efficiency, the power output of each branch is computed and used as an energy sink term in the intermediate volume. The final turbine outlet temperature, after mixing the gas flows of each individual branch, might be higher than that produced for one of the branches and lower than that produced by the other one if they were acting as separate turbines.

The process for computing one single time-step is summarised in Figure 4:

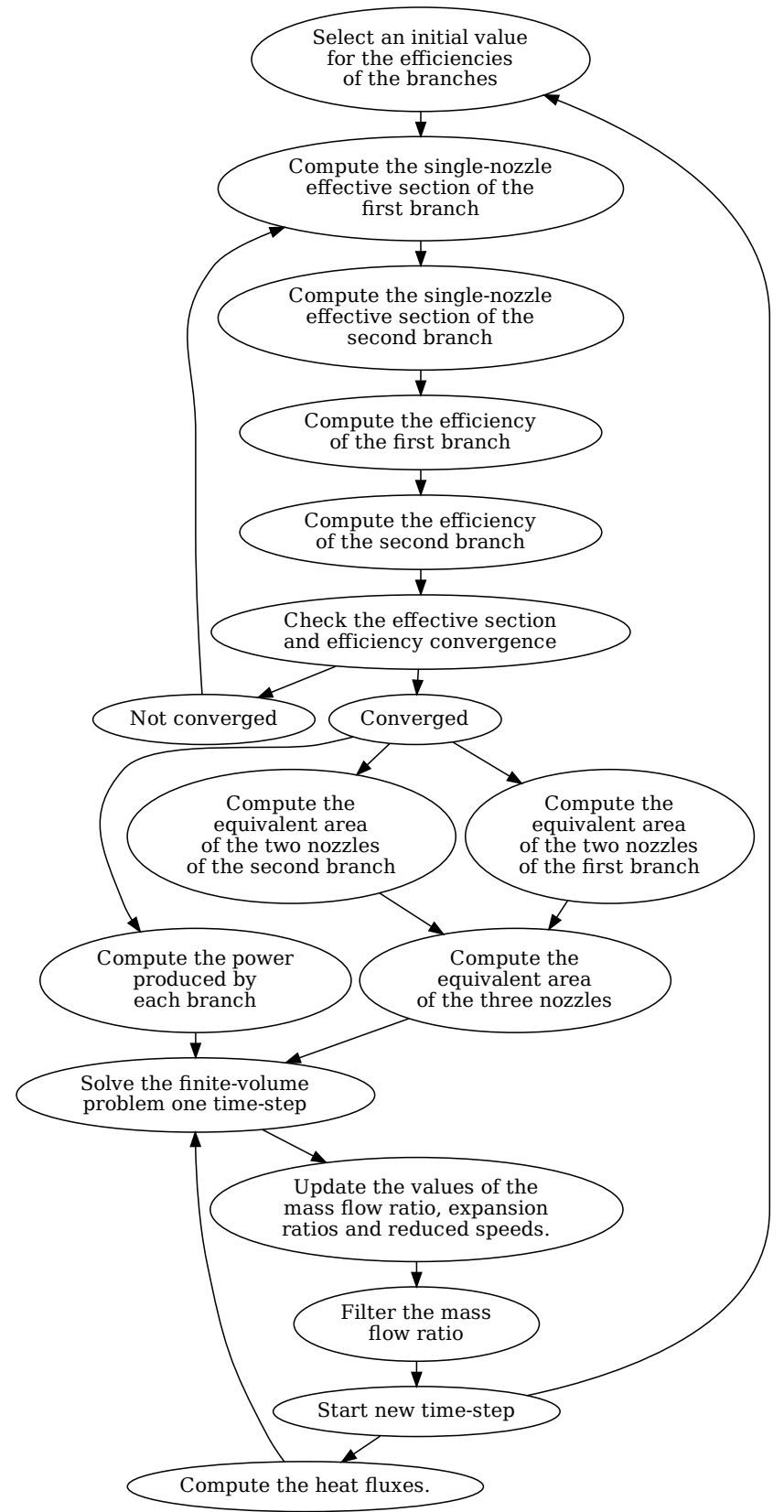

Figure 4. Summary of the steps needed to solve one time-step of the turbine model 


\section{Results}

The objective of this section is to present the performance and potential of the quasi-steady two-scroll turbine model coupled with zero- and one-dimensional elements in terms of non-linear pulses prediction capabilities. To do so, the experimental campaign presented by Serrano et al. [30] is used to obtain the validation results that are next presented. Firstly, a "stationary" validation is presented as a previous step using averaged values of the pulsating tests as an early verification of the implementation. Next, the performance of the model is demonstrated using a turbine characterisation by means of a pressure decomposition under non-linear pulsating excitations. Finally, the instantaneous variation of two important parameters, i.e., the efficiency and the mass flow ratio, is exposed with the intention of making evident how determinant the correct turbine unsteady prediction might be, when it comes to engine-like operating conditions.

\subsection{Steady-state validation}

In addition to the experimental uncertainty and model accuracy, the fully-coupled model might introduce computation instabilities. The authors performed an initial validation against averaged data from the pulsating flow campaign to assess the general accuracy and stability of the model.

First, the fitting parameters of the model were calibrated using an steady-state turbine map obtained as described by Serrano et al. [39]. After that, the model was tested against averaged data by means of the following inputs and outputs:

- Input: Averaged mass and total enthalpy flows are imposed at both turbine inlets.

- Input: Turbocharger speed is imposed.

- Input: Averaged static pressure at the turbine outlet is imposed.

- Output: Expansion ratio in both branches are compared against experimental data.

- Output: Turbine outlet temperature is compared against experimental data.

For this particular validation only the cold conditions operating points have been used, as the aim was only to seek for procedure or implementation errors of the model with as simple as possible operating conditions. Hot operating cases will be properly validated and discussed in the following section.

To assure that the expansion in the turbine is well predicted in terms of pressure drop, the expansion ratio is evaluated separately in shroud and hub branches. In this sense,Figure 5 and Figure 6 show a good agreement between experiments and simulations, with a discrepancy below the $5 \%$ level in the majority of tested conditions. As it can be observed in Figure 7, the turbine outlet temperature is also well predicted, with an error less than $3 \mathrm{~K}$. The model did not present numerical instabilities. Some of the differences between the experimental data and the simulated results come from the averaging of the boundary conditions: the non-linear relationship between the expansion ratio and the mass flow of the turbine introduces discrepancies when comparing steadystate simulations with pulsating experimental data.

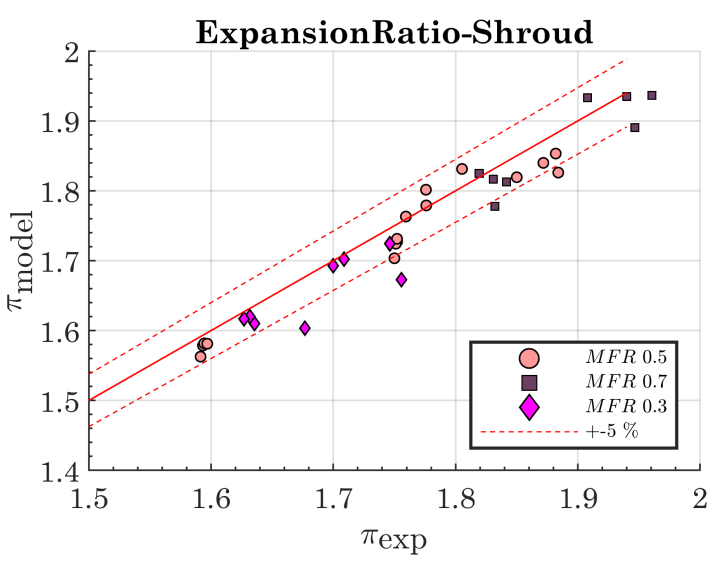

Figure 5. Correlation between experiment and model - expansion ratio in shroud branch

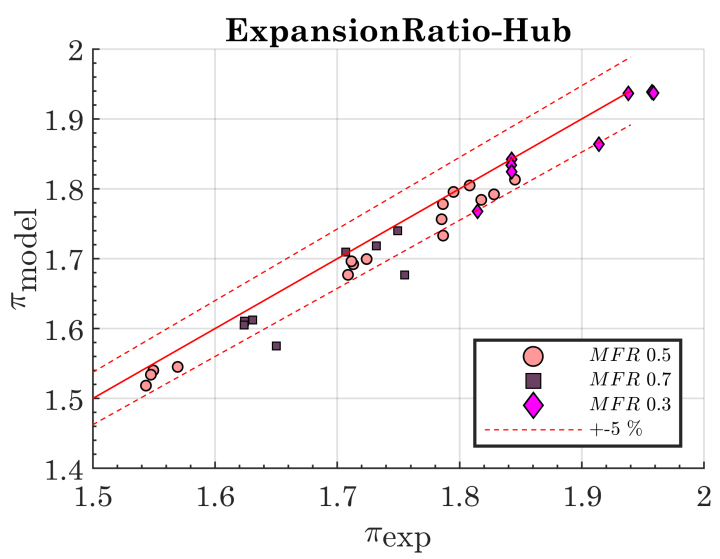

Figure 6. Correlation between experiment and model - expansion ratio in hub branch

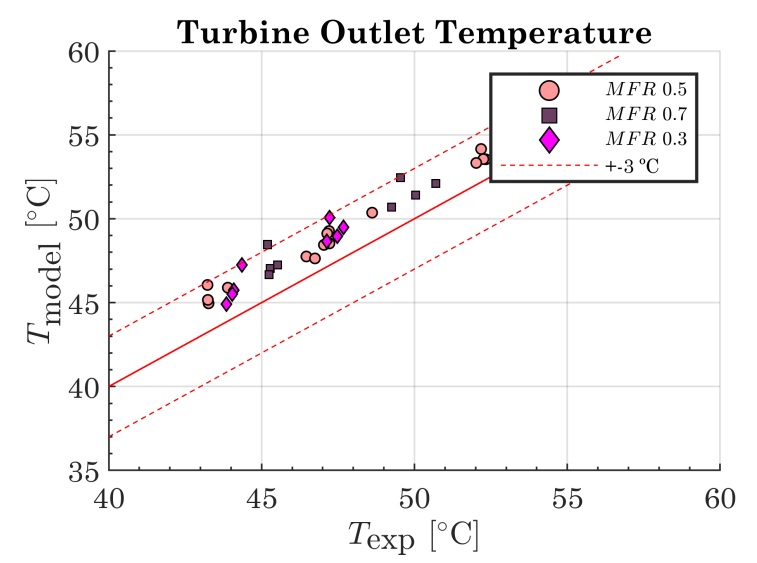

Figure 7. Correlation between experiment and model - expansion ratio in hub branch

\subsection{Pulsating validation}

In the next paragraphs, two operating points obtained from the experimental campaign are presented as examples. These cases represent the performance of the model, and have been selected in a way that the operating conditions were diverse enough. This way, the case correspondent to Figure 8 has been generated in cold conditions and pulsating in shroud branch with $M F R=0.7$. On the other hand, the case presented in Figure 9 has been generated pulsating in the hub 
branch with $M F R=0.3$ and hot conditions. The equivalent engine speed of the excitation is $3900 \mathrm{rpm}$ for the first case and $3700 \mathrm{rpm}$ for the second case. Turbocharger speed is $97 \mathrm{krpm}$ for both cases. The sound pressure level (SPL) from the pressure decomposition results for each turbine branch are presented in different graphs, confronting the experiments with the results provided by the model in both time and frequency domain. The label in the centre of each graph indicates the branch where the pulses are performed, the mass flow ratio and the conditions, following Table 1.

Regarding the nomenclature, incident and reflected are used for the pulsating branch reference the forward and backward travelling waves, i.e., towards and away from the turbine respectively. The same procedure has been used for the nomenclature of the other inlet branch, where indirect reflected and indirect transmitted have been used for the waves moving towards the turbine and away from the turbine respectively. In the outlet branch, the transmitted indicates the wave travelling downstream of the turbine in the direction of the flow, whereas the $2^{\text {nd }}$ reflection wave travels from the outlet of the turbine in the opposite direction of the flow. This naming convention is also presented in Figure 3. 
(a)
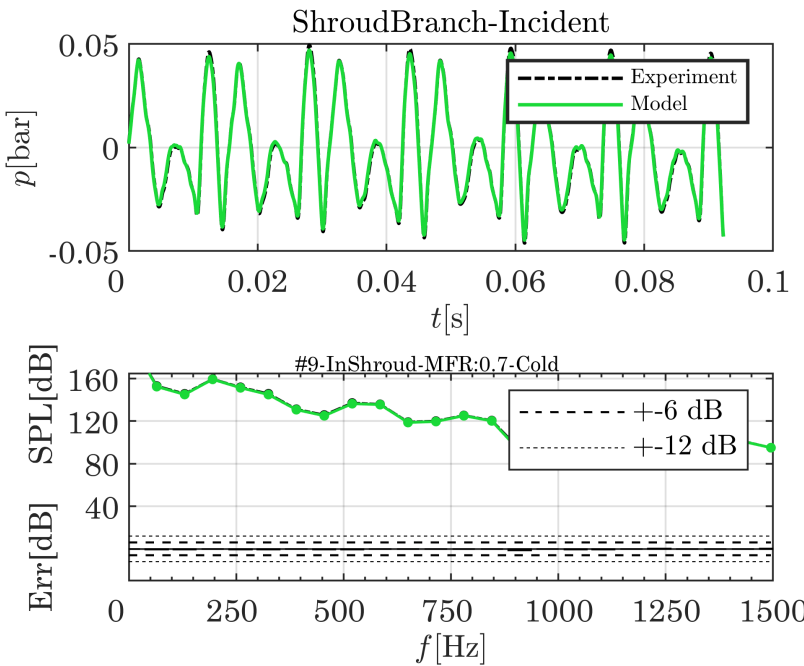

(c)
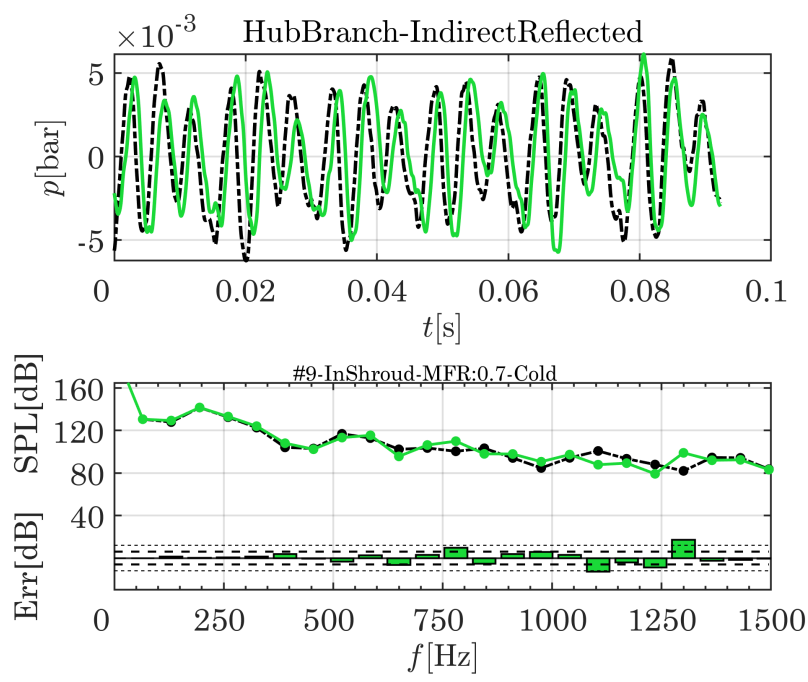

(e)
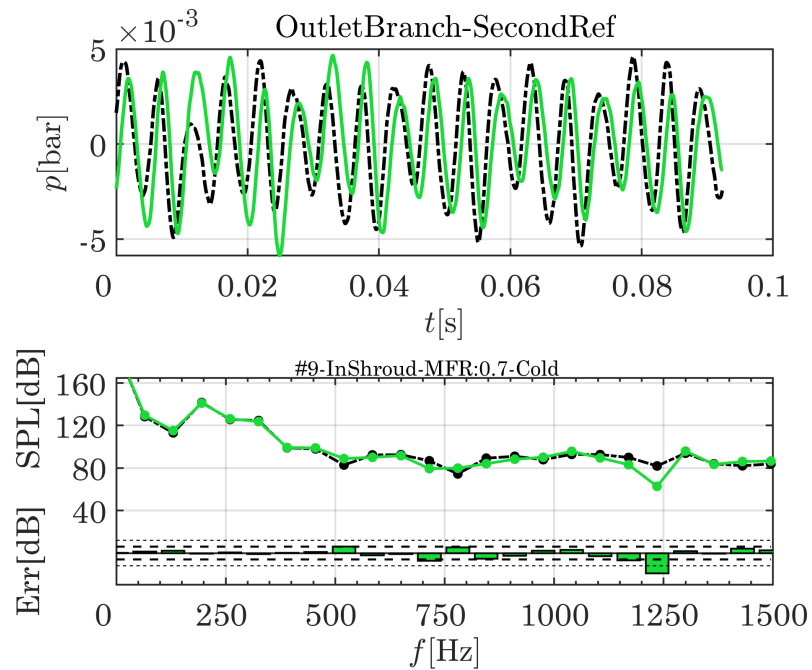

(b)
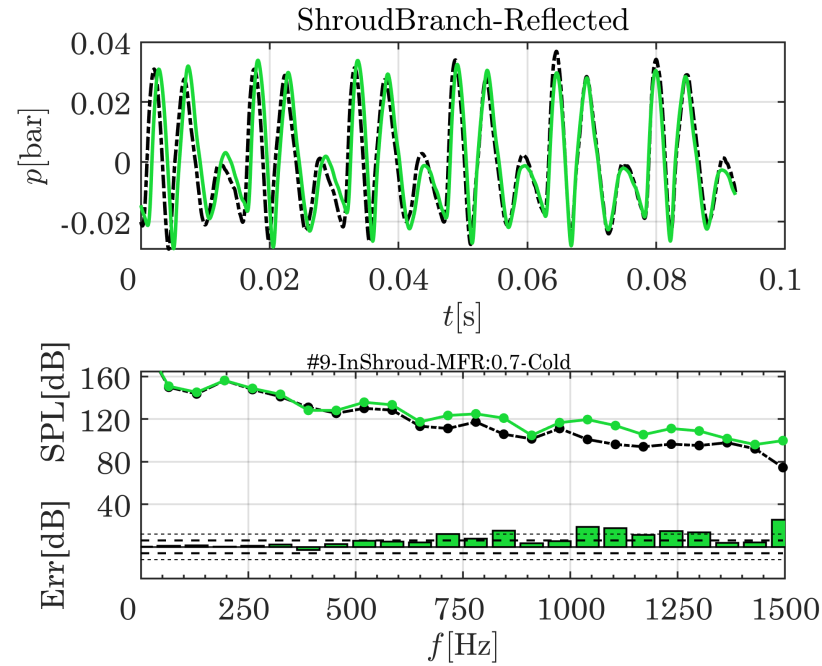

(d)
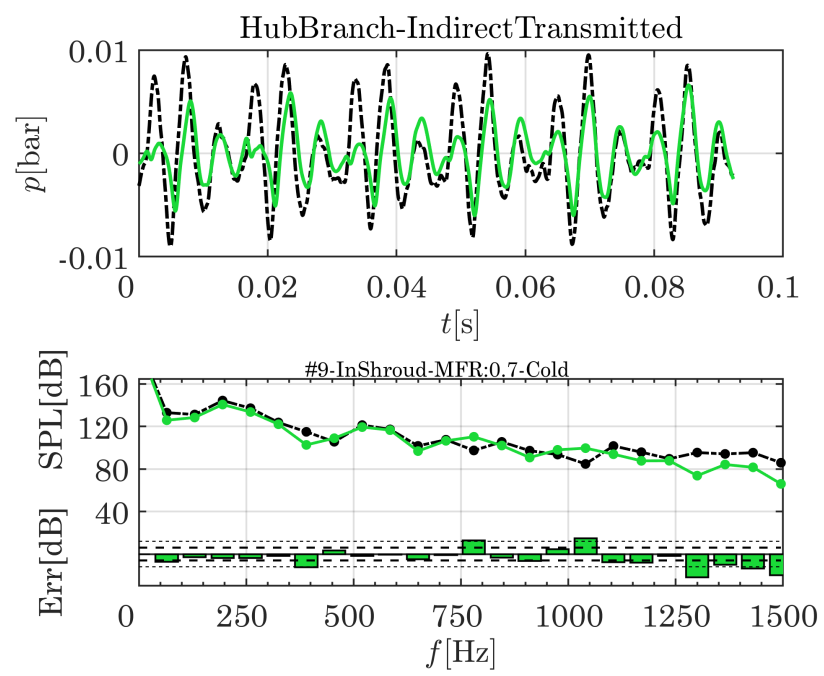

(f)
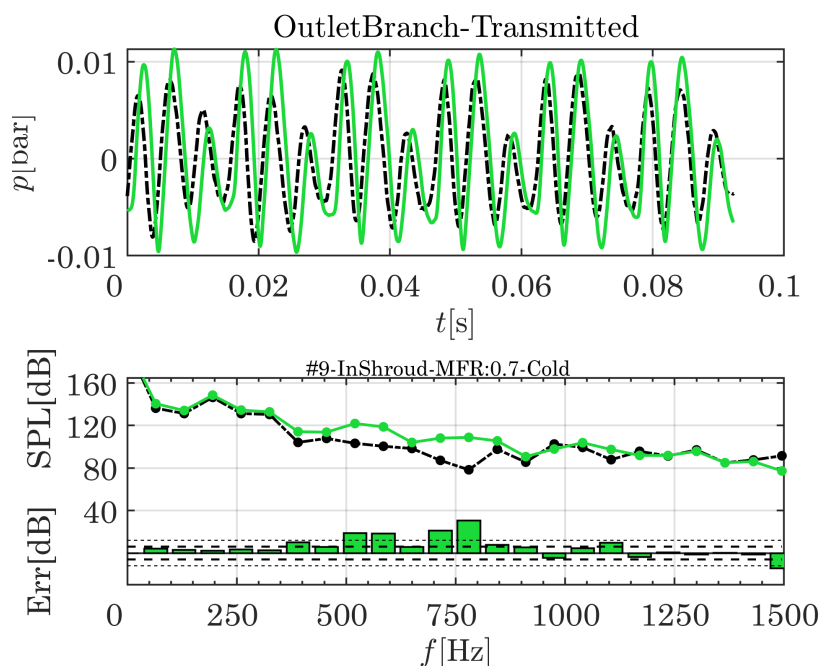

Figure 8. Pressure decomposition results from case 9. Incident, Indirect Reflected and Second Reflection are imposed (a, c and e). Reflected, Indirect Transmitted and Transmitted are computed (b, d and f) 
(a)
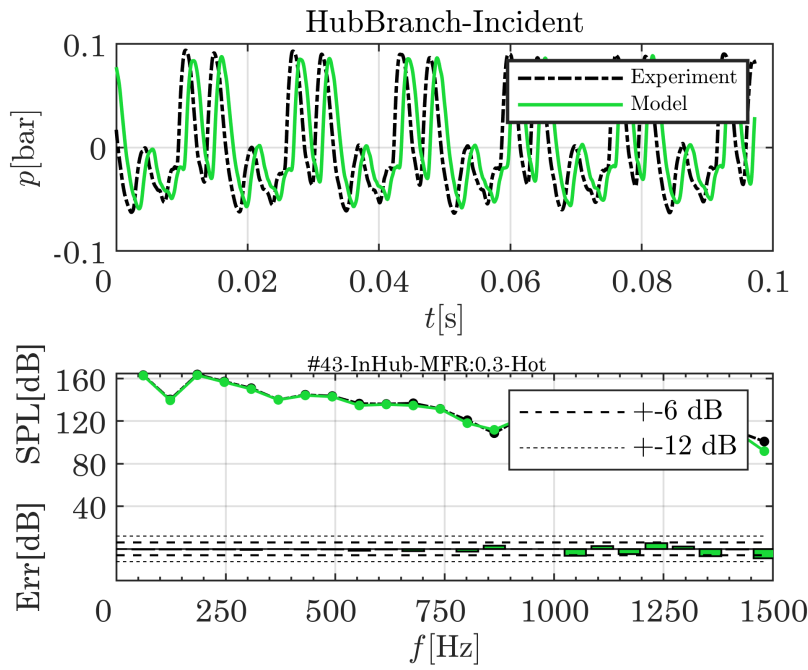

(c)
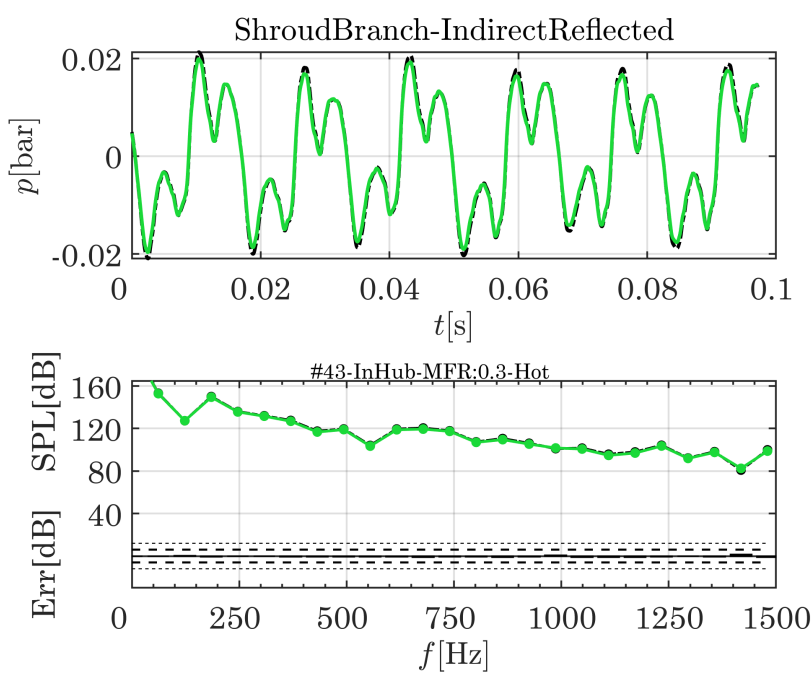

(e)
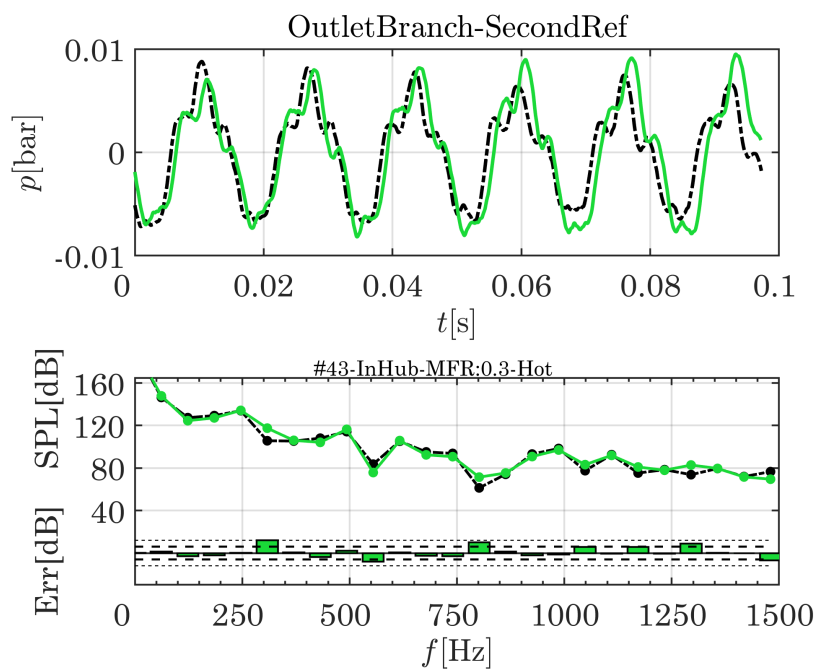

(b)
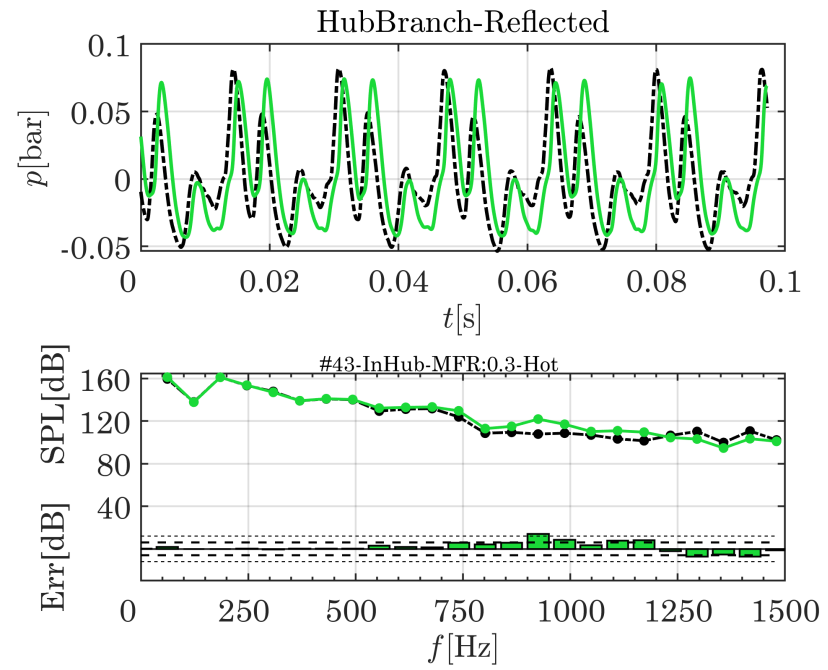

(d)
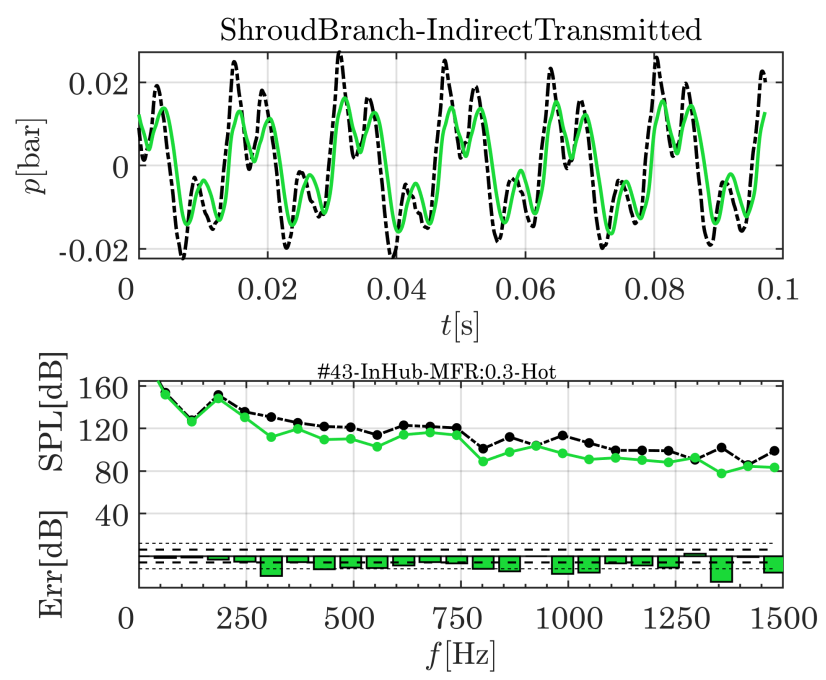

(f)
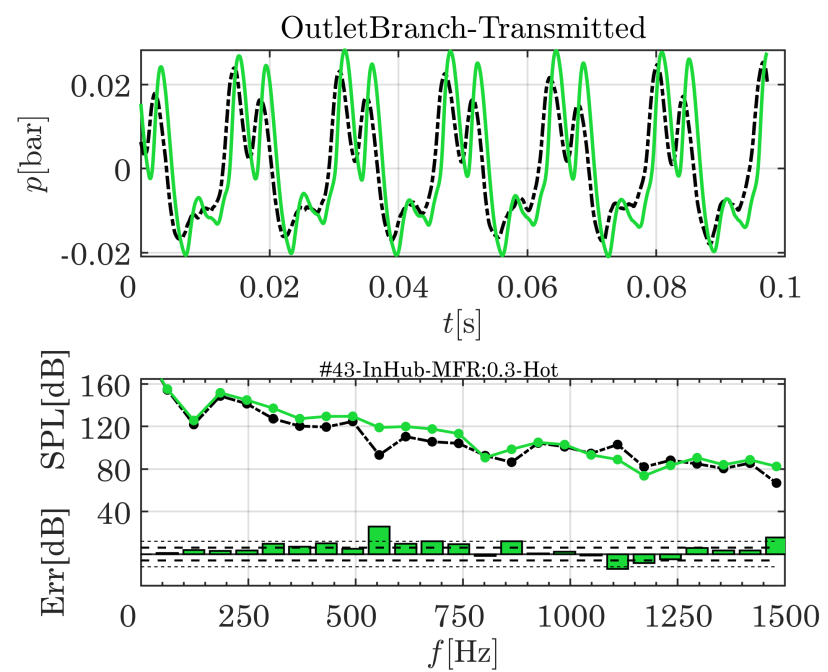

Figure 9. Pressure decomposition results from case 43. Incident, Indirect Reflected and Second Reflection are imposed (a, c and e). Reflected, Indirect Transmitted and Transmitted are computed (b, d and f) 
For performing the simulations, the incident component of the pressure is imposed in the pulsating inlet branch as a boundary condition along with the entropy level. In the same way, the indirect reflected wave is also imposed in the not pulsating inlet branch, whereas the $2^{\text {nd }}$ reflection component is imposed in the outlet branch. In this way, for performing the validation, the capability of the model to predict the reflected and indirect reflected in the inlets, and the transmitted wave in the outlet is evaluated.

In each graph, the time domain result is aimed to check that the geometry of the turbine is correctly modelled and, in consequence, the shape and amplitude of the excitation is well predicted in terms of how it is evolving when it interacts with the different components of the turbine. Nevertheless, results in the time domain do not give easily identifiable information about how the pulse evolves in the turbine in the medium and high frequency spectra. Because of that, the equivalent frequency domain result has been obtained using Fourier's transformation applying a Hann [53] window to a Welch's average periodogram [54]. The frequency domain results are shown in terms of sound pressure level, computed with a reference pressure equal to $0.02 \mathrm{mPa}$. This way, what the bottom part of the graph is presenting is the amplitude in $\mathrm{dB}$ of each harmonic of the equivalent engine.

Figure 8a, Figure 8c, Figure 8e, Figure 9a, Figure 9c and Figure 9e show the pressure waves that are directly imposed as boundary conditions. Focusing in the pulsating branch results presented in Figure $8 \mathrm{~b}$ and Figure $9 \mathrm{~b}$, it can be observed how the reflected component is approximately conserving the shape of the incident, although the amplitude decreases, which is expected due to the attenuation produced once the excitation hits the turbine. The difference in amplitude between both cases is similar to what is found in single-entry turbines [12], being the amplitude of the reflected wave around half of that of the incident pressure wave. Continuing in Figure $8 b$ and Figure $9 b$, it is noteworthy the capability of the model to replicate the reflected component even in the high frequency domain, maintaining the error lower than $6 \mathrm{~dB}$ until almost $1000 \mathrm{~Hz}$ for both cases.

Regarding the other inlet branch, in which the rotating valve is not actuating, some relevant facts can be pointed out from the results obtained. It is interesting to analyse how the wave is transformed when it hits the rotor and travels backwards through the other inlet branch and how this is predicted by the model. To illustrate this with an example, in Figure $8 \mathrm{~b}$ pulses are performed in the shroud branch, so what the indirect transmitted graph represents in Figure $8 \mathrm{~d}$ is the effect that this excitation has produced in the hub branch. From the amplitude of the indirect transmission component it can be inferred that the amplitude has been considerably attenuated when compared to the original incident signal, going from the original amplitude of around $10 \mathrm{kPa}$ in the incident wave of the hot case (Figure 9a), to approximately $2 \mathrm{kPa}$ of the indirect transmitted component (Figure 9d). Nevertheless, the results indicate that, although attenuated, when operating in real engine conditions, the effect of the pulses that will travel to the not pulsating inlet branch are not negligible and might certainly affect the global performance of the engine. Model prediction for the indirect transmitted is not as extremely accurate as in the reflected component, but error is still maintained under the $6 \mathrm{~dB}$ level for the first half of the studied frequency range.

Finally, analysing the effect of the wave that travels through the turbine all the way to the outlet branch, the conclusions are similar than the ones exposed when analysing the indirect transmitted component. The amplitude is also considerably attenuated until the $2 \mathrm{kPa}$ level ( Figure 8f and Figure 9f), but again is not negligible. This implies that when operating in normal conditions, nonlinear pulses will cross the turbine at an still important fraction of their level at the inlet and find their way reaching the aftertreatment line. As it can be observed from the above mentioned figures, the model is still predicting reasonably accurately until medium and high frequencies. The errors in the prediction of the transmitted are however slightly higher, between the $6 \mathrm{~dB}$ and the $12 \mathrm{~dB}$ level. Some of the differences are expected due to the geometrical simplifications used in the model. Also, the experimental uncertainty is higher at the turbine outlet, as the amplitude of the pulses are smaller and it is more complicated to isolate the actual pressure signal from the electromagnetic and thermal noise of the transducers.

These two operating points are representative enough of the general performance of the model, nevertheless, a summary of the results obtained for the complete experimental campaign is showed in Figure 10. In this figure, the Root Mean Square Error (RMSE) of the first 8 harmonics is calculated for the 48 operating points, and plotted against the amplitude. From this result it can be inferred that the discrepancy between the model and the experiments is lower when the amplitude increases, what is consistent with a reduction of the experimental uncertainty with higher amplitude signals.

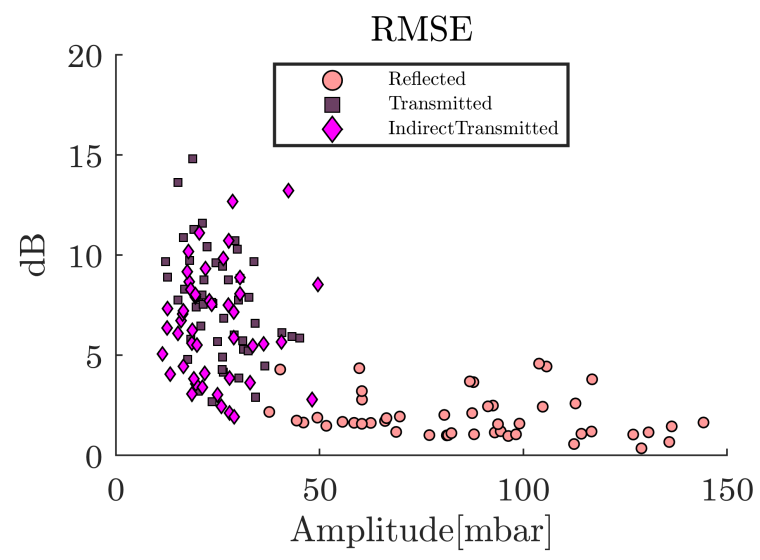

Figure 10. Root mean square error of the model for the harmonics in all the experimental points

A pressure decomposition study is nevertheless, only one of several applications for an integrated turbine model with non-linear prediction capabilities. It is worth studying also some other variables, such as the turbine outlet temperature. In Figure 11 the turbine outlet temperature drop of each operating point of the experiment is presented, i.e., the difference between the maximum and the minimum instantaneous temperature during the pulse for the 48 operating points. 


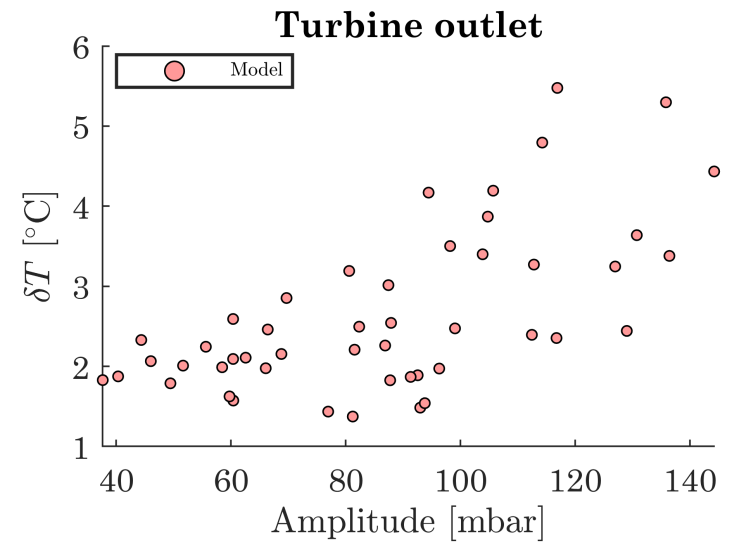

Figure 11. Temperature drop in turbine outlet during a pressure pulse

From Figure 11 it can be stated that high amplitude pulses are generating high oscillations in the outlet temperature with almost $6 \mathrm{~K}$ for the higher amplitude points which, when dealing with higher real engine pulses will probably get over $10 \mathrm{~K}$. Fluctuations in the outlet temperature might affect the exhaust line and the aftertreatment.

\subsection{Apparent efficiency study}

Due to the difficulties in measuring the individual outlet temperature for each turbine branch, it becomes necessary to define an efficiency based on the mixed outlet temperatures of both turbine entries. For such purposes, the apparent efficiency can be analytically expressed as in Equation 10 and Equation 11, which are obtained applying the diagram from Figure 12, explained in detail in previous works[39].

$$
\begin{gathered}
\eta_{\text {shroud }}=\frac{T_{3 \mathrm{t}, \text { shroud }}-T_{5 \mathrm{t}, \mathrm{shroud}}}{T_{3 \mathrm{t}, \mathrm{shroud}}-T_{5 \mathrm{~s}, \mathrm{shroud}}} \\
\eta_{\text {hub }}=\frac{T_{3 \mathrm{t}, \mathrm{hub}}-T_{5 \mathrm{t}, \mathrm{hub}}}{T_{3 \mathrm{t}, \mathrm{hub}}-T_{5 \mathrm{~s}, \mathrm{hub}}}
\end{gathered}
$$

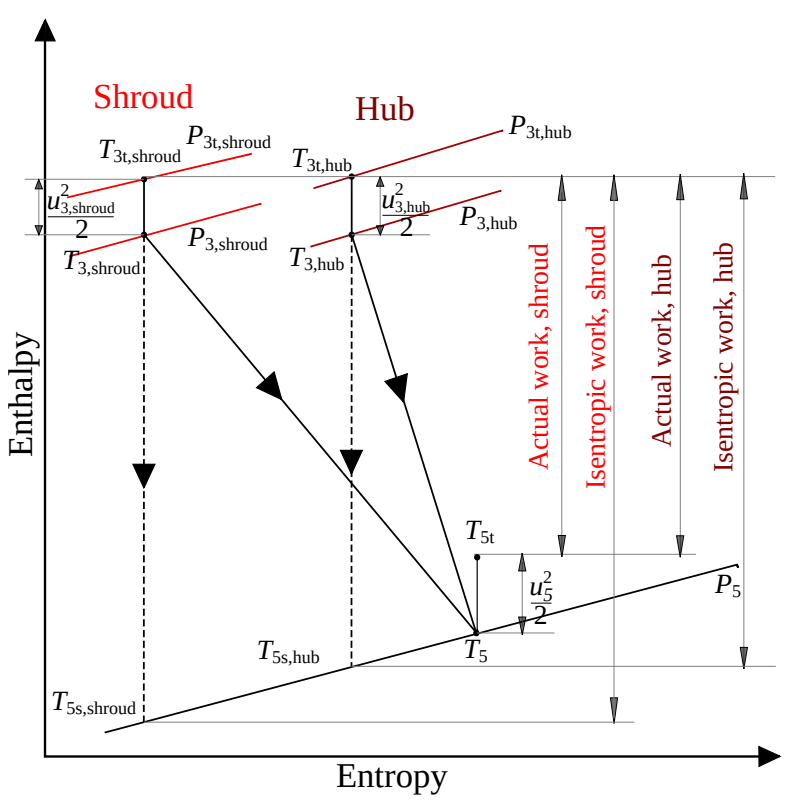

Figure 12. Enthalpy-entropy chart for the expansion process
The objective of this model is not only to predict the nonlinear acoustics, but to help taking better decisions during the design stage and calibration process of the turbocharger and its correspondent engine. In this sense, it is interesting to analyse the instantaneous variation of the efficiency, along with the mass flow ratio and the blade speed ratio. This can be used to give information about the interference effects between branches in terms of actual mass flow and power output of the turbine. In Figure 13, the instantaneous result of the apparent efficiency of the previous example cases after $1 \mathrm{~s}$ of simulation is presented as the independent variable, using the mass flow ratio and the blade speed ratio as dependent variables.

From the results shown in Figure 13, different points can be noted. Firstly, the range of the efficiency is wider in the not pulsating branch results (Figure 13b and Figure 13c), reaching a range of more than 0.12 points in shroud for case 43 . In contrast, the blade speed ratio present its highest variation in the pulsating branch (Figure 13a and Figure 13d), from approximately 0.72 until almost 0.8 . Finally, from the graphs can be inferred that the mass flow ratio presents a modest but not negligible variation, varying from 0.6 to 0.64 for case 9 and from 0.35 to 0.37 for case 43 .

From these results, some interesting results can be inferred:

- Both turbine branches can not be studied as isolated entities to get their mass flow and power output, as there are interference effects between them.

- The apparent efficiency changes in the non-pulsating branch can be large due to the pulses produced in the other branch. In an engine, the branch connected to an exhaust valve that is closed will present these large efficiency changes while its mass flow drops.

- The mass flow ratio can present extra oscillations of moderate amplitude due to the interference of the pressure pulses between turbine inlet branches.

\subsection{Instantaneous mass flow analysis}

A model able to reproduce correctly the non-linear effects of the engine pulses in the turbine can also give valuable information in terms of mass flow. In particular, one of the most interesting analysis that can be carried out is to evaluate the effect that a pulse of the active branch produces in the not pulsating turbine branch. Not in vain, these oscillations travelling upstream of the turbine through the engine might very likely affect the volumetric efficiency.

In Figure 14, the mass flow amplitude is presented. This variable is obtained using the absolute difference between the maximum and the minimum value of the instantaneous mass flow during a pulse for each operating point. In the $x$ axis, the mass flow amplitude reached in the branch where the pulses are performed is presented. On the other hand, the dependent variable is obtained with the quotient between the mass flow amplitude in the not pulsating branch and the mass flow amplitude in the pulsating branch. Thus, this quotient indicates which percentage of the pulse in terms of mass flow is reaching the not pulsating or "passive" branch due to the pulses generated in the active branch.

In view of these results, some considerations can be done: 
(a) Pulsating branch

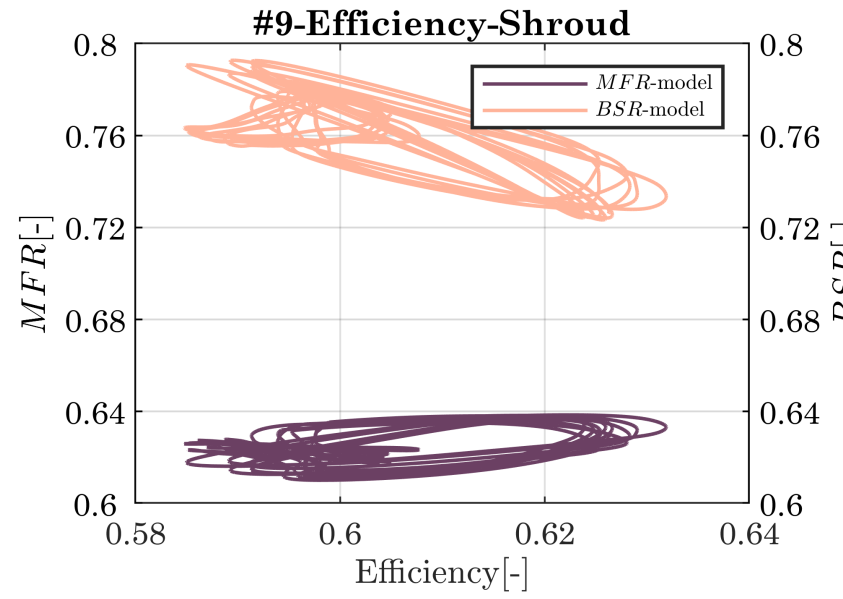

(c) Not pulsating branch

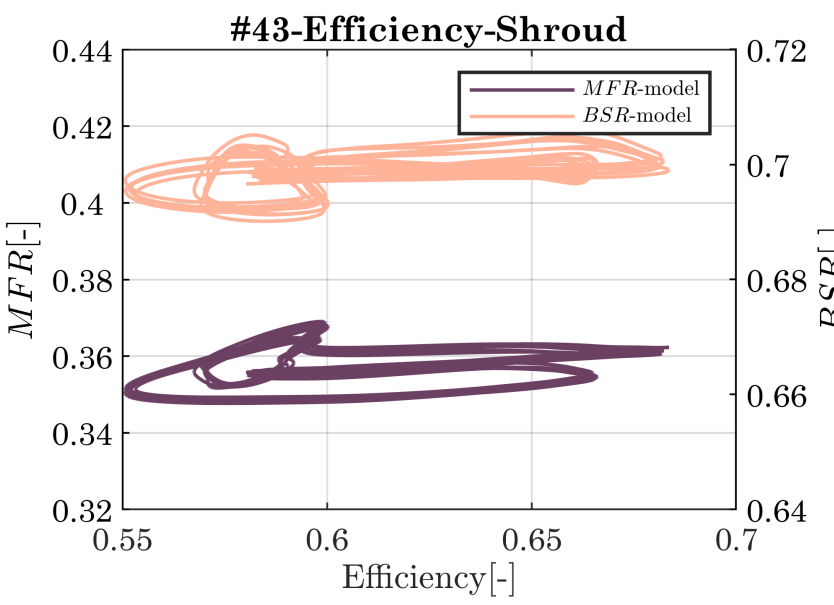

(b) Not pulsating branch

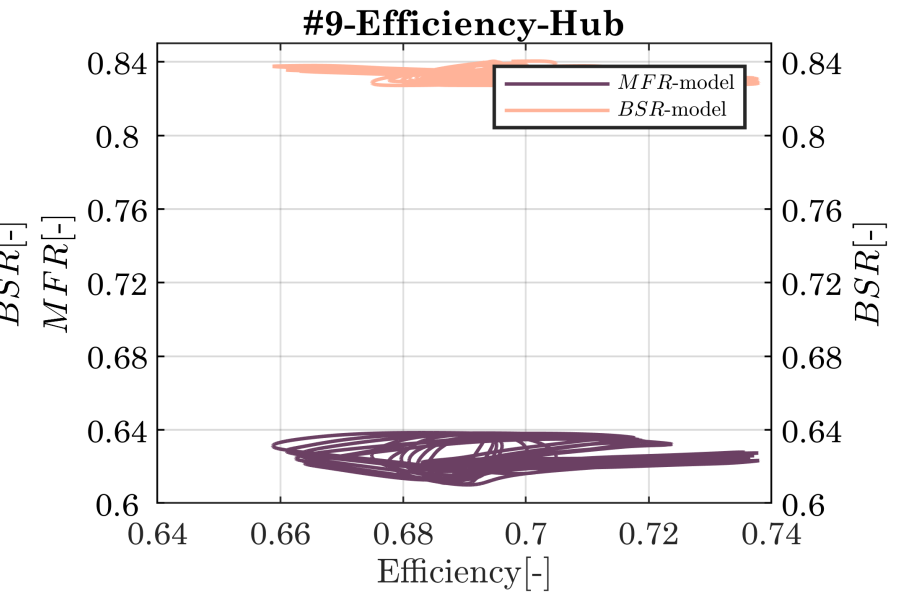

(d) Pulsating branch

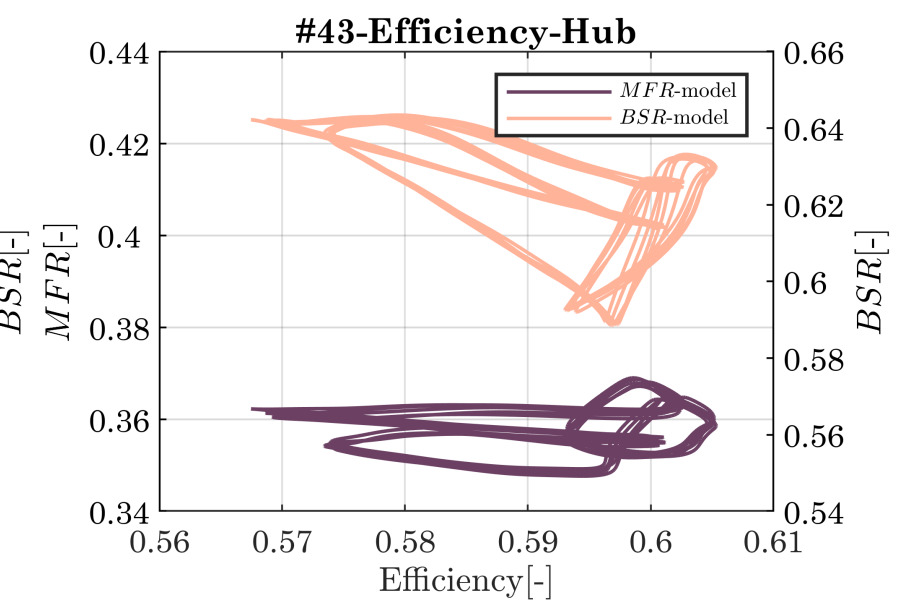

Figure 13. Instantaneous apparent efficiency simulation results. Cases 9 (a, b) and 43 (c and d)

- The effect that the pulses produce in the passive branch in terms of mass flow are probably sufficiently large to affect the performance, specially when the turbine faces real engine pulses generated during transients. In fact, for most of the points, between the $20 \%$ and $30 \%$ of the oscillation manage to travel from the turbine pulsating branch until the outlet and all the way back through the other inlet branch.

- The hot conditions produce bigger amplitude pulses, reaching the level of around $150 \mathrm{~g} \mathrm{~s}^{-1}$ or more. These pulses will lead to bigger transmitted components to the not pulsating branch. The relative effect in the passive branch is not, however, significantly different from the effect produced in the cold cases, as it can be inferred from the values of the quotient between amplitudes.

- For some points in the lower amplitude range (lower than $100 \mathrm{~g} \mathrm{~s}^{-1}$ ), the pulses produced in the hub entry are better transmitted to the other branch that the ones produced in the shroud branch. This could be one of the effects generated by the asymmetry of the turbine entries. Conclusions can vary when analysing other turbochargers, however, the main objective of this section was to illustrate the potential the model.

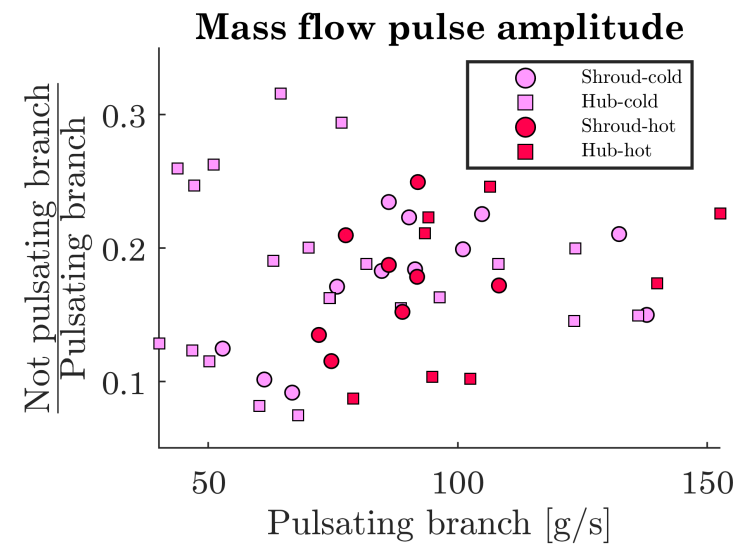

Figure 14. Amplitude of the instantaneous mass flow

\section{Conclusions}

This paper presents a 1D modelling method to predict the two-scroll turbine performance under non-linear pulsating conditions. The model has been validated against experimental data for several simulated engine conditions, i.e., full and partial admission conditions, different equivalent engine speeds, and pulsating in both inlet branches separately for cold and hot flow conditions. 
From the pressure decomposition study, it can be inferred that the model is able to capture the non-linear effects until the medium and sometimes high frequency spectra. The model is less effective when the amplitude is lower, probably due to the higher effect that the experimental uncertainty is producing for these cases. A good level of accuracy is expected when trying to predict real engine conditions.

Although instantaneous experimental results were not obtained for the efficiency due to the difficulties that it implies, the study based on simulation presented indicates that instantaneous variation in the efficiency is significant enough in all the turbine branches to have an impact in the turbine performance. The mass flow ratio range of operation in the contrary is narrower, which opens the possibility of studying different averaged or filtered versions of this parameter without affecting the prediction performance of the model.

From these results it is clear that during the engine exhaust process, interferences are still transmitted between the different turbine branches that will affect the performance of the turbine. The correct modelling of the increasingly used two-scroll turbine under realistic conditions could be very useful when analysing the turbucharger matching, as the low frequency oscillations travelling upstream of the turbine will affect the engine volumetric efficiency and even the turbocharger operating point. Furthermore, a better prediction of the medium and high frequency pulses that are travelling through the exhaust line could lead to a more efficient design of the exhaust line and the muffler. A good prediction of the turbine outlet temperature oscillations due to the pressure pulses should also enable to better compute the aftertreatment behaviour.

From the work presented, the following future study is recommended:

- A complete experimental validation campaign using a dual-volute turbine, with the aim of demonstrating that the model presented is valid for any two-scroll turbine configuration.

- A sensibility study with different mass flow ratio averaging approximations.

The experimental data used in this work is available for download at http://www.cmt.upv.es/DD01.aspx and could be used for other researchers to validate twin turbine models working in pulsating flow conditions.

\section{Acknowledgements}

The authors of this paper wish to thank M.A. Ortiz and R. Carrascosa for their invaluable work during the experimental setup and the campaign.

\section{Funding}

This work has been partially supported by the "Ayuda a Primeros Proyectos de Investigación" (PAID-06-18), Vicerrectorado de Investigación, Innovación y Transferencia de la Universitat Politècnica de València (UPV), València, Spain. Pablo Soler is partially supported through contract FPI-2017-S2-1428 of Programa de Apoyo para la Investigación y Desarrollo (PAID) of Universitat Politècnica de València.

\section{List of symbols}

$\begin{array}{ll}A & \text { Area } \\ a & \text { Speed of sound } \\ B S R & \text { Blade speed ratio } \\ \mathbf{C} & \text { Source terms vector } \\ c_{\mathrm{p}} & \text { Isobaric specific heat capacity } \\ c_{\mathrm{V}} & \text { Isochoric specific heat capacity } \\ \Delta x & \text { Cell size } \\ e_{t} & \text { Specific total internal energy } \\ \eta & \text { Efficiency } \\ \mathbf{F} & \text { Inter-cell fluxes vector } \\ f & \text { Frequency } \\ h & \text { Heat transfer coefficient } \\ \lambda & \text { Eigenvalue } \\ M F R & \text { Mass flow ratio } \\ v & \text { Courant number } \\ \dot{m} & \text { Mass flow } \\ \pi & \text { Total to static pressure ratio } \\ p & \text { Pressure } \\ \dot{Q} & \text { Heat flow } \\ R & \text { Gas constant } \\ T & \text { Temperature } \\ t & \text { Time } \\ u & \text { Flow speed } \\ \dot{W} & \text { Power } \\ \mathbf{w} & \text { State vector } \\ & \end{array}$

$\begin{array}{ll}\text { Subscripts } \\ \text { conv } & \text { Convection } \\ \text { env } & \text { Environment } \\ \text { exp } & \text { Experimental data } \\ \text { hub } & \text { Hub branch } \\ i & \text { Cell number } \\ \text { int } & \text { Internal } \\ \text { min } & \text { Minimum } \\ \text { model } & \text { Model results } \\ \text { s } & \text { Isentropic conditions } \\ \text { shroud } & \text { Shroud branch } \\ \text { surf } & \text { Surface } \\ \mathrm{t} & \text { Total conditions } \\ 0 & \text { Gas stand inlet section } \\ 1 & \text { Turbine inlet section } \\ 2 & \text { Scroll tongue section } \\ 3 & \text { Volute lateral window section } \\ 4 & \text { Vaneless space volume } \\ 5 & \text { Rotor outlet section } \\ 6 & \text { Turbine outlet section } \\ 7 & \text { Gas stand outlet section }\end{array}$

Acronyms

$\mathrm{B} / \mathrm{F} \quad$ Beamforming array

CFD Computational fluid dynamics

CFL Courant-Friedrichs-Lewy condition

CPU Central processing unit

CS Cooling system 


\section{LS Lubrication system}

MUSCL Monotone Upstream-centered Schemes for Conservation Laws

SPL Sound pressure level

VGT Variable geometry turbine

\section{References}

1. Knopf M. How low can we go? Downsizing the internal combustion engine. Ingenia 2011; URL https: //www.ingenia.org.uk/Ingenia/Articles/ $11612 c 67-32 \mathrm{db}-477 \mathrm{a}-\mathrm{af} 8 \mathrm{f}-38 \mathrm{cef} 44 \mathrm{ee} 7 \mathrm{~b} 2$.

2. Hogg R. Life beyond euro VI. automotiveworld 2014; URL http://www.automotiveworld.com/ megatrends-articles/life-beyond-euro-vi/.

3. Watson $\mathrm{N}$ and Janota $\mathrm{M}$. Turbocharging the internal combustion engine. The Macmillan Press Ltd 1982;

4. Galindo J, Fajardo P, Navarro R et al. Characterization of a radial turbocharger turbine in pulsating flow by means of CFD and its application to engine modeling. Applied Energy 2013; 103(0): 116 - 127. DOI:10.1016/j.apenergy.2012.09.013.

5. Winterbone D, Nikpour B and Frost H. A contribution to the understanding of turbocharger turbine performance in pulsating flow. In Proceedings of the Institution of Mechanical Engineers. pp. 19-30. Paper C433/011.

6. Winterbone $\mathrm{D}$ and Pearson R. Turbocharger turbine performance under unsteady flow-a review of experimental results and proposed models. IMechE conference transactions 1998; 11: 193-208.

7. Torregrosa AJ, Broatch A, Navarro R et al. Acoustic characterization of automotive turbocompressors. International Journal of Engine Research 2015; 16(1): 31-37. DOI:10.1177/ 1468087414562866.

8. Serrano JR, Tiseira A, García-Cuevas LM et al. Radial turbine performance measurement under extreme off-design conditions. Energy 2017; 125: 72-84. DOI:10.1016/j.energy. 2017.02.118

9. Torregrosa A, Serrano J, Dopazo J et al. Experiments on wave transmission and reflection by turbochargers in engine operating conditions. In SAE 2006 World Congress \& Exhibition. SAE International. DOI:10.4271/2006-01-0022. SAE Technical Paper 2006-01-0022.

10. Hohenberg KG, Newton PJ, Martinez-Botas RF et al. Development and experimental validation of a low order turbine model under highly pulsating flow. In Turbo Expo: Power for Land, Sea, and Air, Volume 2C: Turbomachinery. ASME, p. V02CT44A023. DOI:10.1115/GT2017-63983. 2017.

11. Piscaglia F, Onorati A, Marelli S et al. A detailed one-dimensional model to predict the unsteady behavior of turbocharger turbines for internal combustion engine applications. International Journal of Engine Research 2019; 20(3): 327-349. DOI:10.1177/1468087417752525.

12. Galindo J, Arnau FJ, García-Cuevas LM et al. Experimental validation of a quasi-two-dimensional radial turbine model. International Journal of Engine Research 2018; DOI:10.1177/ 1468087418788502

13. Cappelaere N, Dazin A and Bois G. An industrial experimental methodology for the unsteady characterization of automotive turbocharger. In 16th International Symposium on Transport Phenomena and Dynamics of Rotating Machinery. 2016.
14. Baines N, Hajilouy-Benisi A and Yeo J. The pulse flow performance and modelling of radial inflow turbines. In 5 th International Conference on Turbochargers, Inst Mech Eng, London, Paper C48400694. pp. 209-219. 1994.

15. Rajoo S, Romagnoli A and Martinez-Botas RF. Unsteady performance analysis of a twin-entry variable geometry turbocharger turbine. Energy 2012; 38(1): 176-189. DOI: 10.1016/j.energy.2011.12.017.

16. Rajoo S and Martinez-Botas RF. Variable Geometry Mixed Flow Turbine for Turbochargers: An Experimental Study. International Journal of Fluid Machinery and Systems 2008; 1(1): 155-168. DOI:10.5293/IJFMS.2008.1.1.155.

17. Copeland CD, Martinez-Botas RF and Seiler M. Comparison Between Steady and Unsteady Double-Entry Turbine Performance Using the Quasi-Steady Assumption. Journal of Turbomachinery 2011; 133(3): 031001. DOI:10.1115/1.4000580.

18. Copeland CD, Martinez-Botas RF and Seiler M. Unsteady Performance of a Double Entry Turbocharger Turbine With a Comparison to Steady Flow Conditions. Journal of Turbomachinery 2012; 134(2): 021022. DOI:10.1115/1. 4003171.

19. Costall AW, McDavid RM, Martinez-Botas RF et al. Pulse Performance Modeling of a Twin Entry Turbocharger Turbine Under Full and Unequal Admission. Journal of Turbomachinery 2011; 133(2): 021005. DOI:10.1115/1. 4000566.

20. Yang M, Martinez-Botas RF, Rajoo S et al. Influence of Volute Cross-Sectional Shape of a Nozzleless Turbocharger Turbine Under Pulsating Flow Conditions. In ASME Turbo Expo 2014: Turbine Technical Conference and Exposition Volume 2D: Turbomachinery. ASME, p. V02DT42A025. DOI:10. 1115/GT2014-26150.

21. Yang M, Martinez-Botas RF, Rajoo S et al. An investigation of volute cross-sectional shape on turbocharger turbine under pulsating conditions in internal combustion engine. Energy Conversion and Management 2015; 105: 167-177. DOI: 10.1016/j.enconman.2015.06.038.

22. Copeland CD, Newton PJ, Martinez-Botas RF et al. The Effect of Unequal Admission on the Performance and Loss Generation in a Double-Entry Turbocharger Turbine. Journal of Turbomachinery 2012; 134(2): 021004. DOI:10.1115/1. 4003226.

23. Cerdoun $M$ and Ghenaiet A. Unsteady behaviour of a twin entry radial turbine under engine like inlet flow conditions. Applied Thermal Engineering 2018; 130: 93-111. DOI:10. 1016/j.applthermaleng.2017.11.001.

24. Payri F, Benajes J and Reyes M. Modelling of supercharger turbines in internal-combustion engines. International Journal of Mechanical Sciences 1996; 38(8): 853 - 869. DOI:10.1016/ 0020-7403(95)00105-0.

25. Chiong MS, Rajoo S, Martinez-Botas RF et al. Engine turbocharger performance prediction: One-dimensional modeling of a twin entry turbine. Energy Conversion and Management 2012; 57: 68-78. DOI:10.1016/j.enconman.2011.12.001.

26. Macek J, Zak Z and Vitek O. Physical Model of a Twin-scroll Turbine with Unsteady Flow. In SAE 2015 World Congress \& Exhibition. DOI:10.4271/2015-01-1718. SAE Technical Paper 2015-01-1718.

27. Chiong MS, Rajoo S, Romagnoli A et al. Assessment of Partial-Admission Characteristics in Twin-Entry Turbine Pulse Performance Modelling. In ASME Turbo Expo 
2015: Turbine Technical Conference and Exposition Volume 2C: Turbomachinery. p. V02CT42A022. DOI:10.1115/ GT2015-42687.

28. Chiong MS, Rajoo S, Romagnoli A et al. One-dimensional pulse-flow modeling of a twin-scroll turbine. Energy 2016; 115: 1291-1304. DOI:10.1016/j.energy.2016.09.041.

29. Kabral R, El Nemr Y, Ludwig C et al. Experimental acoustic characterization of automotive twin-scroll turbine. In 12th European Conference on Turbomachinery Fluid Dynamics and Thermodynamics, ETC 2017. p. 363. 2017.

30. Serrano J, Arnau F, Garcia-Cuevas L et al. An Experimental Method to Test Twin and Double Entry Automotive Turbines in Realistic Engine Pulse Conditions. In WCX SAE World Congress Experience. DOI:10.4271/2019-01-0319. SAE Technical Paper 2019-01-0319.

31. Galindo J, Navarro R, García-Cuevas LM et al. A zonal approach for estimating pressure ratio at compressor extreme off-design conditions. International Journal of Engine Research 2019; 20(4): 393-404. DOI:10.1177/ 1468087418754899.

32. Payri F, Olmeda P, Arnau FJ et al. External heat losses in small turbochargers: Model and experiments. Energy 2014; 71: 534 - 546. DOI:10.1016/j.energy.2014.04.096.

33. Serrano JR, Olmeda P, Arnau FJ et al. Turbocharger heat transfer and mechanical losses influence in predicting engines performance by using one-dimensional simulation codes. Energy 2015; 86: 204 - 218. DOI:10.1016/j.energy. 2015.03.130.

34. Gil A, Tiseira A, García-Cuevas LM et al. Fast threedimensional heat transfer model for computing internal temperatures in the bearing housing of automotive turbochargers. International Journal of Engine Research 2018; DOI:10.1177/ 1468087418804949.

35. Serrano JR, Olmeda P, Tiseira A et al. Theoretical and experimental study of mechanical losses in automotive turbochargers. Energy 2013; 55(0): 888 - 898. DOI:10.1016/j. energy.2013.04.042.

36. Pinero G, Vergara L, Desantes JM et al. Estimation of velocity fluctuation in internal combustion engine exhaust systems through beamforming techniques. Measurement Science and Technology 2000; 11(11): 1585. DOI:10.1088/0957-0233/11/ 11/307.

37. Baar R, Biet C, Boxberger $\mathrm{V}$ et al. New Evaluation of Turbocharger Components based on Turbine Outlet Temperature Measurements in Adiabatic Conditions. In 15th International Symposium on Transport Phenomena and Dynamics of Rotating Machinery. 2014.

38. Zimmermann R, Baar R and Biet C. Determination of the isentropic turbine efficiency due to adiabatic measurements and the validation of the conditions via a new criterion. Proceedings of the Institution of Mechanical Engineers, art C: Journal of Mechanical Engineering Science 2018; 232(24): 4485-4494. DOI:10.1177/0954406216670683.

39. Serrano J, Arnau F, García-Cuevas L et al. Experimental approach for the characterization and performance analysis of twin entry radial-inflow turbines in a gas stand and with different flow admission conditions. Applied Thermal Engineering 2019; 159: 113737. DOI:10.1016/j.applthermaleng. 2019.113737.

40. Serrano JR, Olmeda P, Páez A et al. An experimental procedure to determine heat transfer properties of turbochargers.
Measurement Science and Technology 2010; 21(3): 035109. DOI:10.1088/0957-0233/21/3/035109.

41. Serrano JR, Arnau FJ, Dolz V et al. A model of turbocharger radial turbines appropriate to be used in zero- and onedimensional gas dynamics codes for internal combustion engines modelling. Energy Conversion and Management 2008; 49(12): 3729 - 3745. DOI:10.1016/j.enconman.2008.06.031.

42. Serrano JR, Arnau FJ, Fajardo P et al. Contribution to the Modeling and Understanding of Cold Pulsating Flow Influence in the Efficiency of Small Radial Turbines for Turbochargers. Journal of Engineering for Gas Turbines and Power 2012; 134(10): 571-580. DOI:10.1115/GT2012-68422.

43. Serrano JR, Arnau FJ, García-Cuevas LM et al. Development and validation of a radial turbine efficiency and mass flow model at design and off-design conditions. Energy Conversion and Management 2016; 128: 281 - 293. DOI:10.1016/j. enconman.2016.09.032.

44. Chen $\mathrm{H}$ and Winterbone D. A method to predict performance of vaneless radial turbine under steady and unsteady flow conditions. In IMechE 4th International Conference on Turbocharging and Turbochargers. Institution of Mechanical Engineers, pp. 13-22. 1990.

45. Chen H, Hakeem I and Martínez-Botas RF. Modelling of a turbocharger turbine under pulsating inlet conditions. In Proceedings of the Institution of Mechanical Engineers, Part A: Journal of Power and Energy. Institution of Mechanical Engineers, pp. 397-408. 1996.

46. CMT - Motores Térmicos, Universitat Politècnica de València. openWAM, 2016. URL http: / / www . openwam. org/.

47. Galindo J, Serrano JR, Arnau FJ et al. Description of a SemiIndependent Time Discretization Methodology for a OneDimensional Gas Dynamics Model. Journal of Engineering for Gas Turbines and Power 2009; 131(3): 034504. DOI: 10.1115/1.2983015.

48. Godunov SK. A difference scheme for numerical solution of discontinuous solution of hydrodynamic equations. Matematicheskii Sbornik 1959; 47: 271-306.

49. van Leer B. Towards the Ultimate Conservation Difference Scheme. II. Monotonicity and Conservation Combined in a Second-Order Scheme. Journal of Computational Physics 1974; 14: 361. DOI:10.1016/0021-9991(74)90019-9.

50. Toro E, Spruce M and Speares W. Restoration of the contact surface in the HLL-Riemann solver. Shock Waves 1994; 4(1): 25-34. DOI:10.1007/BF01414629.

51. Courant R, Friedrichs $K$ and Lewy $H$. Über die partiellen differenzengleichungen der mathematischen physik. Mathematische Annalen 1928; 100(1): 32-74. DOI:10.1007/ bf01448839.

52. Serrano J, Arnau F, Garcéa-Cuevas L et al. Development of flow oriented model for extrapolation and interpolation offdesign performance of twin-entry and dual volute radial-inflow turbines working under different flow admission conditions. Energy; Under review.

53. Harris F. On the use of windows for harmonic analysis with the discrete fourier transform. In Proceedings of the IEEE, volume 66. IEEE, pp. 51-83. DOI:10.1109/PROC.1978. 10837.

54. Welch P. The use of fast fourier transform for the estimation of power spectra: A method based on time averaging over short, modified periodograms. IEEE Transactions on Audio Electroacoustics 1967; 15: 70-73. DOI:10.1109/TAU.1967. 
1161901 